\title{
Pharmaceuticals and personal care products in water and wastewater: a review of treatment processes and use of photocatalyst immobilized on functionalized carbon in AOP degradation
}

\author{
Adewumi Olufemi Oluwole, Elizabeth Oyinkansola Omotola and Olatunde Stephen Olatunji
}

\begin{abstract}
The presence of emerging contaminants such as pharmaceutical and personal care products in many aqueous matrices have been reported. One of such matrix is streams of wastewater, including wastewater treatment plants inflows and outflows and wastewater flow by-passing wastewater treatment plants. Their persistence arises from their resistant to breakdown, hence they may remain in the environment over long time, with a potential to cause adverse effects including endocrine disruption, gene toxicity, the imposition of sex organs, antibiotic resistance and many others in some aquatic organisms exposed to arrays of residues of pharmaceutical and personal care products. Among the treatment techniques, advanced oxidation processes have been reported to be a better technique through which these PPCPs can be degraded in the WWTPs. Heterogeneous photocatalysis using various photocatalyst immobilized on solid support such as activated carbon, graphene and carbon nanotubes in AOPs have been shown to be a viable and efficient method of PPCPs degradation. This is because, the performance of most WWTPs is limited since they were not designed to degrade toxic and recalcitrant PPCPs. This review highlight the occurrence, concentration

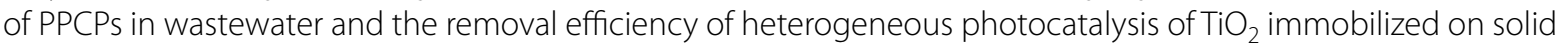
supports.
\end{abstract}

Keywords: Ppcps, Wastewater, WWTPs, AOPs, Heterogeneous photocatalysis, Photocatalyst immobilized, Activated carbon/graphene/carbon nanotubes solid support, PPCPs degradation, Removal efficiency

\section{Introduction}

The expansion in the world's population, economic development, the industrial revolution, and climate change has led to an increase in the quantity of waste generation as well as an increase in the introduction of specific categories of compounds referred to as emerging contaminants, into the environments. The U.S. Environmental Protection Agency (EPA) described "emerging contaminants" as chemicals or materials which were previously not listed

*Correspondence: olatunjio@ukzn.ac.za

School of Chemistry and Physics, University of KwaZulu-Natal, Westville,

Durban 4000, South Africa for routine monitoring, characterized by a perceived potential or real threat to human and environmental health, and lacks published health standard, environmental protection laws, and regulations [1]. According to the U.S. Geological Survey (USGS), emerging contaminants are "any synthetic or naturally occurring chemical or any microorganism that is not usually investigated in the environment but can find its way into the environment and cause known or suspected adverse ecological and/or human health effects". Hence, there is an urgent need to develop methods for the removal of these emerging contaminants from the environment. 
Emerging contaminants can be classified into several groups, which include; perfluorinated compounds (PFCs), pharmaceuticals and personal care products (PPCPs), brominated flame retardants (BFRs), microplastics and toxins from harmful algal blooms, etc. [2, 3]. Concerns about the potentially adverse effects of these substances on human and ecosystem health are arising from their persistence, environmental accumulation tendency, exposure potential, bioaccumulation/biomagnification potential, and bioactivity. These contaminants may, therefore, be prioritized for regulation, depending on the information pool from monitoring data regarding their occurrence, their toxicity, potential health effects, and public perception.

A significant index factor of public and community health is access to good quality water, which is imperatively crucial for all life forms. The pollution of the water system may result in an outbreak of water-borne diseases, which can have acute or long-term health implications and even death. Humans and animals are susceptible to these diseases because polluted water is mostly the exposure pathway to infectious pathogens and carcinogenic organic and inorganic contaminants. For instance, while the dissolution of active pharmaceutical ingredients (APIs) in aqueous matrices is variable; they are primarily water-soluble and have such properties that allow them to permeate membranes and persist in the biological systems. The inherent properties of APIs, however, raise questions about their environmental risk, the potential for accumulation, and bioactivity within an aquatic environment [4]. As with administered dosages on target organisms, pharmaceuticals are capable of altering biochemical and physiological processes in many non-target organisms. Hence, their capacity to induced undesirable consequences on native and peripatetic species of organisms exposed to APIs contaminated environment.

Although the presence of PPCPs in the environment has been noticed for some years now, the full extent of their presence and the risk associated with their presence in the environment has not been fully established. Also, the removal of these contaminants in wastewater treatment (WWTPs), before their discharge into surface water has proven to be difficult due to their low occurrence concentrations, and the challenges arising from analyzing them [5]. Therefore, there is a need to modify and upgrade the existing WWTPs to be able to resolve or remove these contaminants. The conventional wastewater treatment methods which include; physical, chemical or combination of physicochemical process, involving the following: filtration, flocculation, coagulation process, sedimentation, biological processes, membrane filtration, chlorination, adsorption process via activated carbon $(\mathrm{AC})$, carbon nanotubes (CNTs), graphene oxide
(GO), ozonation, photo-catalysis ultraviolet irradiation, ultra-sonication, and others. Unfortunately, these methods cannot adequately remove organic pollutants from wastewater. In addition to the processes being chemically and operationally intensive, they require large systems, infrastructure, and engineering expertise, which make them burdensome, ineffective, time-consuming, and costly $[6,7]$.

Moreover, the use of nano-adsorbents in the removal of PPCPs from water matrices has been associated with some challenges, among which are smaller particle size, generation of secondary pollutants, inability to reuse, or regenerate etc. Also, the use of semiconductors as catalysts in the degradation of PPCPs encounter the following drawbacks such as; requirement for high ultraviolet radiation for their activities due to wide bandgap energy within them; some are carcinogenic, e.g., $\mathrm{TiO}_{2}$; there is also the challenge with electron-hole pair recombination after use $[8,9]$. Hence, the need to design materials that are green, economically efficient and effective methods for pollution control and prevention are needed for environmental protection and effluent discharge to have minimal impacts on human health and the biosphere.

Consequently, the advanced oxidation process (AOP) has been reported to be one of the most promising methods that can be employed for mineralization of complex organic pollutants as an effective alternative technique that involves the in-situ generation of strong oxidation radicals sufficient enough to degrade and eliminate organic pollutants within environmental matrices.

AOP is efficient in the removal of hazardous pollutants and their mineralization into non-toxic inorganic aliphatic acid, $\mathrm{CO}_{2}$ and water as compared to other decontamination techniques like; adsorption, coagulation, flocculation, sedimentation, bio-filtration, etc., as a result of the generation of active oxidizing agents such as hydroxyl radicals, superoxide, ozonide and photo-produced electron-hole pairs [10-12]. AOP can be achieved by direct ozonolysis, catalytic oxidation, homogenous/ heterogeneous catalyzed oxidation, with the more recent advances in photocatalytic oxidation which is one of the green technologies that has attracted scientific interest as viable alternatives for the treatment of wastewater because of its low operating cost, nontoxicity, and effective reduction of contaminants $[13,14]$.

Over the years, efforts have been directed towards synthesizing various nanocomposites for photocatalysis purposes. This technique is one of the most preferred AOP because it offers the possibility of utilizing naturally available and renewable solar energy as a potential energy source containing visible light in the presence of a suitable photocatalyst prepared from metal oxides or semiconductors as catalyst immobilized on various solid 
supports for the photodegradation of pharmaceuticals. Unfortunately, the photocatalytic performance of most semiconductor photocatalyst is still low due to lack of enough active sites, large band gap, utilization of photons from the sun, and limited fast photoinduced charge carrier recombination [12, 15]. Hence, the development of efficient and highly stable photocatalysts with increased light absorption in the visible spectrum, reduced band gap, and decreased rapid electron-hole pairs recombination rate is necessary for the photocatalytic degradation of organic pollutants under visible light.

Hence, the aim of this review is to discuss the occurrence of pharmaceuticals and personal care products in the environment, highlights the failure of the conventional methods in degrading pharmaceuticals and personal care products from the water matrices and why photocatalytic degradation processes of pharmaceuticals and personal care products via the use of various semiconductor photocatalyst immobilized either on other semiconductors, metal oxide or on different carbon sources such as activated carbon, carbon nanotubes, and graphene oxides has been able to degrade these organic pollutants to propose more alternative nanomaterial that is green, efficient, non-toxic, cheap and more effective with a short time for the photocatalytic degradation of different organic pollutants.

\section{Pharmaceuticals and personal care products (PPCPs)}

Pharmaceuticals and personal care products (PPCPs) consists of APIs, moisturizers, lipsticks, shampoos, hair colors, deodorants, toothpaste surfactant, and many household products that are mainly used for improving the quality of daily life [16] and their degradation products have been inadvertently present in the aquatic environment since the 1970s [17]. Their residues have been detected in all types of surface water, groundwater, and the oceanic environment in the last 20 years [18]. These compounds find their way into many aquatic environments receiving contaminated water from urban wastewater streams (domestic/industrial discharges, WWTPs effluents, etc.), which in turn get transferred into the water cycle, even reaching drinking water, as a result of their hydrophilic character and low removal efficiency of wastewater treatment plants (WWTPs).

Pharmaceuticals generally include prescription or over the counter (OTC) veterinary/human drugs and nutraceuticals administered for prophylaxis/therapeutic and health supplements purposes. They are classified as antibiotics, analgesics, blood lipid regulators, natural and synthetic hormones, $\beta$-blockers, anti-diabetics, antihypertensive, and many more products that are used for health purposes [19]. These substances are continuously discharged into the aquatic environment from a point and non-point domestic and industrial sources.

\section{Presence and occurrence of pharmaceuticals and personal care products in wastewater}

A global survey has indicated the presence of several classes of PPCPs in most aquatic environments. Unfortunately, these data rely primarily on studies conducted in Europe, North America, Scandinavia, and a few other places. The availability of such data in those parts of the world is because research on PPCPs and many endocrine disruption contaminants/pollutants in African Countries and especially in the South Africa aquatic system is scanty $[20,21]$. Despite the lack of data, the occurrence of some PPCPs at concentration levels that sometimes surpassed $\mu \mathrm{g} / \mathrm{L}$ level in WWTPs effluents and environmental waters have been reported [22-24]. Research studies on remediation of contaminated/polluted aqueous matrices and or the removal of these contaminants in drinking treatment plants and or during wastewater treatment before discharge to surface water is still far behind and probably lacking.

Commonly detected pharmaceuticals in different environmental matrices and their occurrence levels are as listed in Table 1 below.

\section{Classification of pharmaceuticals and personal care products}

Pharmaceuticals can be classified into different active organic groups of compounds $[44,45]$. These include but not limited to; (i) antibiotics which comprise penicillin, tetracycline, sulfonamides, macrolides, fluoroquinolones, and $\beta$ lactams; (ii) steroids hormones many of which have been implicated as endocrine-disrupting compounds such as estrogens, estrone, estriol, $17-\beta$-estradiol, $17-\alpha$-ethinylestradiol, testosterone, etc. (iii) analgesic and non-steroidal anti-inflammatory drugs (NSAIDS) which are one of the most prescribed groups of pharmaceuticals that include acetaminophen, diclofenac, ibuprofen, and naproxen; (iv) antiepileptic drugs such as carbamazepine, used in reducing the frequency of epileptic seizures; (v) blood lipid regulators, e.g., bezafibrate, gemfibrozil, fenofibric acid and clofibric acid; (vi) $\beta$-blockers such as salbutamol, atenolol, sotalol, theophylline and metoprolol used in treating hypertension and cardiac dysfunctions; (vii) antineoplastic such as cytostatic drugs used in cancer therapy; etc. Antimicrobial agents, fungicides, disinfectants, synthetic musks, some preservatives, some sunscreen UV filters, etc., may also be referred to as pharmaceuticals depending on the description of use.

Personal Care Products (PCPs) groups include; (i) pesticides/insect repellants, (ii) musk; widely used as fragrances of many personal care products such as; 
Table 1 Commonly detected PPCPs in different environmental matrices and their occurrence levels around the world

\begin{tabular}{|c|c|c|c|c|}
\hline PPCPs & Concentration $(\mu \mathrm{g} / \mathrm{L})$ & Country & Source & References \\
\hline \multirow[t]{8}{*}{ Sulfamethoxazole } & $0.33-0.61$ & Beijing & River and sewage water & {$[25]$} \\
\hline & 2.00 & Australia & Surface water & {$[26]$} \\
\hline & 3.00 & Australia & Wastewater treatment plant influent & {$[26]$} \\
\hline & 0.20 & Australia & Wastewater treatment plant effluent & {$[26]$} \\
\hline & 34.50 & Kwazulu-Natal, South Africa & Wastewater treatment plant influent & {$[24]$} \\
\hline & 3.68 & Kwazulu-Natal, South Africa & Surface water & [22] \\
\hline & 0.049 & Scaynes Hill, UK & Wastewater treatment plant influent & {$[27]$} \\
\hline & 0.023 & Scaynes Hill, UK & Wastewater treatment plant effluent & {$[27]$} \\
\hline \multirow[t]{6}{*}{ Nalidixic acid } & $1.73-30.84$ & Kwazulu-Natal, South Africa & Surface water & {$[22]$} \\
\hline & 29.9 & Kwazulu-Natal, South Africa & WWTW influent & {$[28]$} \\
\hline & 25.2 & Kwazulu-Natal, South Africa & WWTW effluent & {$[28]$} \\
\hline & 0.20 & Australia & WWTW influent & {$[26]$} \\
\hline & 0.45 & Australia & WWTW effluent & {$[26]$} \\
\hline & 0.75 & Australia & Hospital effluent; Wastewater treatment plant & {$[26]$} \\
\hline \multirow[t]{11}{*}{ Aspirin } & 0.664 & South Wales, UK & Cilfynydd wastewater treatment influent & {$[29]$} \\
\hline & 0.027 & South Wales, UK & Cilfynydd wastewater treatment effluent & {$[29]$} \\
\hline & 2.49 & South Wales, UK & Coslech Wastewater treatment Influent & [29] \\
\hline & 0.02 & South Wales, UK & Coslech Wastewater treatment effluent & [29] \\
\hline & 2.566 & Catalonia, Spain & Wastewater Influent & {$[30]$} \\
\hline & 0.034 & Catalonia, Spain & Wastewater effluent & {$[30]$} \\
\hline & 0.012 & Catalonia, Spain & Surface Water & {$[30]$} \\
\hline & 874 & Canada & Influent sewage treatment plants & {$[31]$} \\
\hline & 59.6 & Canada & Effluent sewage treatment plants & {$[31]$} \\
\hline & 118.00 & Kwazulu-Natal, South Africa & Wastewater treatment plant influent & {$[28]$} \\
\hline & 44.20 & South Africa & Wastewater treatment plant effluent & {$[28]$} \\
\hline \multirow[t]{8}{*}{ Naproxen } & 0.838 & South Wales, UK & Cilfynydd wastewater treatment influent & {$[29]$} \\
\hline & 0.37 & South Wales, UK & Cilfynydd wastewater treatment effluent & {$[29]$} \\
\hline & 1.173 & South Wales, UK & Coslech wastewater treatment influent & {$[29]$} \\
\hline & 0.17 & South Wales, UK & Coslech wastewater treatment effluent & {$[29]$} \\
\hline & 5.938 & Korea & WWTP influent & {$[32]$} \\
\hline & 0.120 & Korea & WWTP effluent & {$[32]$} \\
\hline & $52.30-55.00$ & Gauteng, South Africa & WWTP influent & {$[23]$} \\
\hline & $13.50-20.40$ & Gauteng, South Africa & WWTP effluent & {$[23]$} \\
\hline \multirow[t]{9}{*}{ Ibuprofen } & 1.68 & South Wales, UK & Cilfynydd wastewater treatment influent & {$[29]$} \\
\hline & 0.26 & South Wales, UK & Cilfynydd wastewater treatment effluent & {$[29]$} \\
\hline & 2.29 & South Wales, UK & Coslech wastewater treatment influent & {$[29]$} \\
\hline & 0.14 & South Wales, UK & Coslech wastewater treatment effluent & {$[29]$} \\
\hline & $5-8$ & Canada & Wastewater effluent & {$[33]$} \\
\hline & 62.82 & Kwazulu-Natal, South Africa & WWTW influent & {$[24]$} \\
\hline & 58.71 & Kwazulu-Natal, South Africa & WWTW effluent & {$[24]$} \\
\hline & 9.494 & Korea & WWTP influent & {$[32]$} \\
\hline & 0.015 & Korea & WWTP effluent & {$[32]$} \\
\hline
\end{tabular}


Table 1 (continued)

\begin{tabular}{|c|c|c|c|c|}
\hline PPCPs & Concentration $(\mu \mathrm{g} / \mathrm{L})$ & Country & Source & References \\
\hline \multirow[t]{8}{*}{ Acetaminophen } & 211.38 & South Wales, UK & Cilfynydd wastewater treatment influent & [29] \\
\hline & 11.73 & South Wales, UK & Cilfynydd wastewater treatment effluent & [29] \\
\hline & 178.12 & South Wales, UK & Coslech wastewater treatment influent & [29] \\
\hline & 0.35 & South Wales, UK & Coslech wastewater treatment effluent & [29] \\
\hline & 11.3 & France & WWTP influents & {$[34]$} \\
\hline & 5.76 & Kwazulu-Natal, South Africa & WWTW influent & [24] \\
\hline & 74.552 & Korea & WWTP influent & [32] \\
\hline & 0.023 & Korea & WWTP effluent & {$[32]$} \\
\hline \multirow[t]{7}{*}{ Carbamazepine } & 1.69 & South Wales, UK & Cilfynydd wastewater treatment influent & [29] \\
\hline & 2.49 & South Wales, UK & Cilfynydd wastewater treatment effluent & [29] \\
\hline & 0.95 & South Wales, UK & Coslech wastewater treatment influent & [29] \\
\hline & 0.83 & South Wales, UK & Coslech wastewater treatment effluent & [29] \\
\hline & 1.9 & Canada & Wastewater treatment influent & [31] \\
\hline & 2.3 & Canada & Wastewater treatment influent & [31] \\
\hline & 0.42 & Tainan, Taiwan & WWTP effluent & [35] \\
\hline \multirow[t]{8}{*}{ Diclofenac } & 22.3 & Kwazulu-Natal, South Africa & Wastewater treatment plant influent & {$[28]$} \\
\hline & 12.4 & Kwazulu-Natal, South Africa & Wastewater treatment plant effluent & [28] \\
\hline & $15.3-19.4$ & Germany & Wastewater treatment plant & [19] \\
\hline & $0.21-0.49$ & France & WWTP effluents & {$[34]$} \\
\hline & 0.397 & Scaynes Hill, UK & Wastewater treatment plant influent & {$[27]$} \\
\hline & 0.119 & Scaynes Hill, UK & Wastewater treatment plant effluent & {$[27]$} \\
\hline & 0.251 & Sapporo, Japan & Municipal wastewater treatment plant influent & {$[36]$} \\
\hline & 0.145 & Sapporo, Japan & Municipal wastewater treatment plant effluent & {$[36]$} \\
\hline \multirow[t]{4}{*}{ Tetracyclines } & 0.10 & Australia & WWTW influent & {$[26]$} \\
\hline & 0.02 & Australia & WWTW effluent & {$[26]$} \\
\hline & $0.6-5.7$ & Kwazulu-Natal, South Africa & Surface water & {$[22]$} \\
\hline & $0.003-0.008$ & Tianjin China & Municipal wastewaters influents & {$[37]$} \\
\hline \multirow[t]{7}{*}{ Bisphenol A } & 1.52 & Tianjin China & Municipal wastewaters influents & {$[37]$} \\
\hline & $0.190-1.0789$ & Harbin city, China & Wastewater influents & {$[38]$} \\
\hline & $0.0614-0.1755$ & Harbin city, China & Wastewater effluent & {$[38]$} \\
\hline & 0.028 & Pretoria and Cape Town, South Africa & Drinking water & {$[39]$} \\
\hline & 0.002 & Germany & Drinking water & {$[40]$} \\
\hline & 0.047 & Germany & Sewage Treatment effluents & {$[40]$} \\
\hline & 0.014 & Germany & River Water & {$[40]$} \\
\hline Triclosan & $78.40-127.70$ & Gauteng, South Africa & WWTP influent & {$[23]$} \\
\hline \multirow[t]{2}{*}{ Benzophenone } & $1.5-8.58$ & Nagpur city, India & Sewage treatment plant & {$[41]$} \\
\hline & $10.70-22.90$ & Gauteng, South Africa & WWTP effluent & {$[23]$} \\
\hline \multirow[t]{5}{*}{ Estrone } & $0013-0.351$ & Kwazulu-Natal, South Africa & WWTW influent & {$[42]$} \\
\hline & $0.078-0.158$ & Tianjin China & Municipal wastewaters influents & {$[37]$} \\
\hline & $0.003-0.078$ & Kwazulu-Natal, South Africa & WWTW effluent & {$[42]$} \\
\hline & $0.0102-0.0349$ & Harbin city, China & Wastewater influents & {$[38]$} \\
\hline & $0.0083-0.014$ & Harbin city, China & Wastewater effluents & {$[38]$} \\
\hline
\end{tabular}


Table 1 (continued)

\begin{tabular}{|c|c|c|c|c|}
\hline PPCPs & Concentration $(\mu \mathrm{g} / \mathrm{L})$ & Country & Source & References \\
\hline \multirow[t]{6}{*}{ 17- $\beta$-Estradiol } & $0.02-0.199$ & Kwazulu-Natal, South Africa & WWTW influent & [42] \\
\hline & $0.004-0.107$ & Kwazulu-Natal, South Africa & WWTW effluent & [42] \\
\hline & $0.011-0.054$ & Tianjin China & Municipal wastewaters influents & [37] \\
\hline & $0.0466-0.093$ & Harbin city, China & Wastewater influents & [38] \\
\hline & $0.0087-0.0324$ & Harbin city, China & Wastewater effluents & [38] \\
\hline & 0.0041 & California, USA & Municipal wastewater effluent & [43] \\
\hline \multirow[t]{2}{*}{ Estriol } & $0.003-0.009$ & Kwazulu-Natal, South Africa & WWTW influent & [42] \\
\hline & $0.042-0.162$ & Tianjin China & Municipal wastewaters influents & [37] \\
\hline \multirow[t]{2}{*}{ Progesterone } & $0.163-0.904$ & Kwazulu-Natal, South Africa & WWTW influent & [42] \\
\hline & 0.025 & Kwazulu-Natal, South Africa & WWTW effluent & [42] \\
\hline \multirow[t]{2}{*}{ Testosterone } & $0.119-0.635$ & Kwazulu-Natal, South Africa & WWTW influent & [42] \\
\hline & 0.026 & Kwazulu-Natal, South Africa & WWTW influent & [42] \\
\hline
\end{tabular}

perfume, body lotion, hair care products, shower bath products facial essence and numerous household products, (iii) soaps and detergents, (iv) sunscreen UV filters, which are chemicals that serve as absorbers and protection of the skin from different ultraviolet radiations from UV-induced damages, (v) triclosan; a lipid-soluble, broad-spectrum, antimicrobial agents which are used as preservatives in personal care products such as hand soap, shampoos, detergents, toothpaste, sunscreen, deodorants, and (vi) antiseptic which serves various purposes in medical devices, household items and as additives in packaging textiles and functional clothing [46-48]. Some of their structures are given in Fig. 1

\section{Source of PPCPs in the environment}

The global annual consumption of PPCPs in developed world and countries such as Brazil, Russia, India, China, and South Africa has been reported to have increased over the last decade, due to their medical use for prophylaxis/therapy, and economic use for viability sustenance of commercial aquaculture and livestock agriculture [49]. As a result, residues of compounds of PPCPs are continuously released into wastewater via wash-off, urine, and feces as parent compounds, derivative conjugates, or metabolites [50]. PPCPs can also enter the surface water through direct discharge from industries [51], hospitals, household's/domestic wastewater and through surface runoff (as result of the use of contaminated biosolids as manure spread on agricultural land), reaching water bodies and groundwater by leaching or bank filtration. Other means through which PPCPs enter into the aquatic environment include disposal of unused medicines into landfills, irrigation with wastewater, off-label emissions, and disposal of carcasses of treated animals [52], and sewage or wastewater treatment plants [53, 54]. Brauschet al. [55] reported that the WWTPs are the main route through which PPCPs are discharged into the aquatic environment. They have been found in lakes, rivers, groundwater, marine, and coastal area waters and drinking water $[45,56,57]$.

Aquatic sediments can also hold a substantial amount of PPCPs because of their affinity binding/sorption capacity [58]. Thus, excess PPCPs do not remain in the water for long, as they partition between water, sediment, and other components of the aquatic ecosystem, via diffusion, seeding, silting out of suspended particle bondedPPCPs and other physical/chemical processes. Aside from the application of contaminated biosolids on farmland soils, several PPCPs reach the soil and different terrestrial domain through the deposition (air/wet) of short and long-range atmospheric transferred aerodynamic sized PPCPs particulates [59]. A schematic diagram showing potential sources and pathways of pharmaceuticals is shown in Fig. 2.

\section{Transformation of PPCPS and their metabolites}

The soluble characteristics and bioactive nature of many pharmaceuticals and some personal care products may facilitate their biotransformation and depuration in biological features. However, this is not the case with most PPCPs in the environment, where they do not readily degrade. Many pharmaceuticals are discharged from the human and animal bodies in a mixture of their parent compound and conjugate metabolites [61, 62]. The extent of body metabolism and pharmacokinetics index is a function of the ratio between the parent compound (unmetabolized) and the conjugate metabolites concentrations measured in urine or feces $[63,64]$. They may also 
<smiles>C/C=C(\O)CC(C)(C)Cc1ccc(C(C)C(=O)O)cc1</smiles>

Albendazole<smiles>CN(C)[C@H]1C(O)=C(C(N)=O)C(=O)[C@]2(O)C(O)=C3C(=O)c4c(O)cccc4[C@@H](O)[C@H]3C[C@H]12</smiles>

Tetracycline<smiles>CCOC(=O)OCCOc1ccc2cc([C@@H](C)C(=O)O[GaH2])ccc2c1</smiles><smiles>CC(C)(C)c1ccc(O)cc1</smiles><smiles>Cc1cc(NS(=O)(=O)c2ccc(N)cc2)no1</smiles><smiles>Cc1c(C(=O)NCCO)[n+]([O-])c2ccccc2[n+]1[O+]=O</smiles><smiles>CCCOCC</smiles>

$\mathrm{Cl}$<smiles>Oc1cc(Cl)ccc1Oc1ccc(Cl)cc1Cl</smiles><smiles>NC(=O)N1c2ccccc2C=Cc2ccccc21</smiles>

Carbamazipine

Fig. 1 Structures of some pharmaceuticals and personal care products

undergo environmental transformation under certain conditions (enviro-kinetic).

Monitoring metabolites of pharmaceuticals in the environment is, however, limited by the lack of reference standards of environment bound pharmaceutical metabolites, resulting in the scanty information on the occurrence levels, behavior, and half-life of conjugates metabolites in the environment. For instance, 


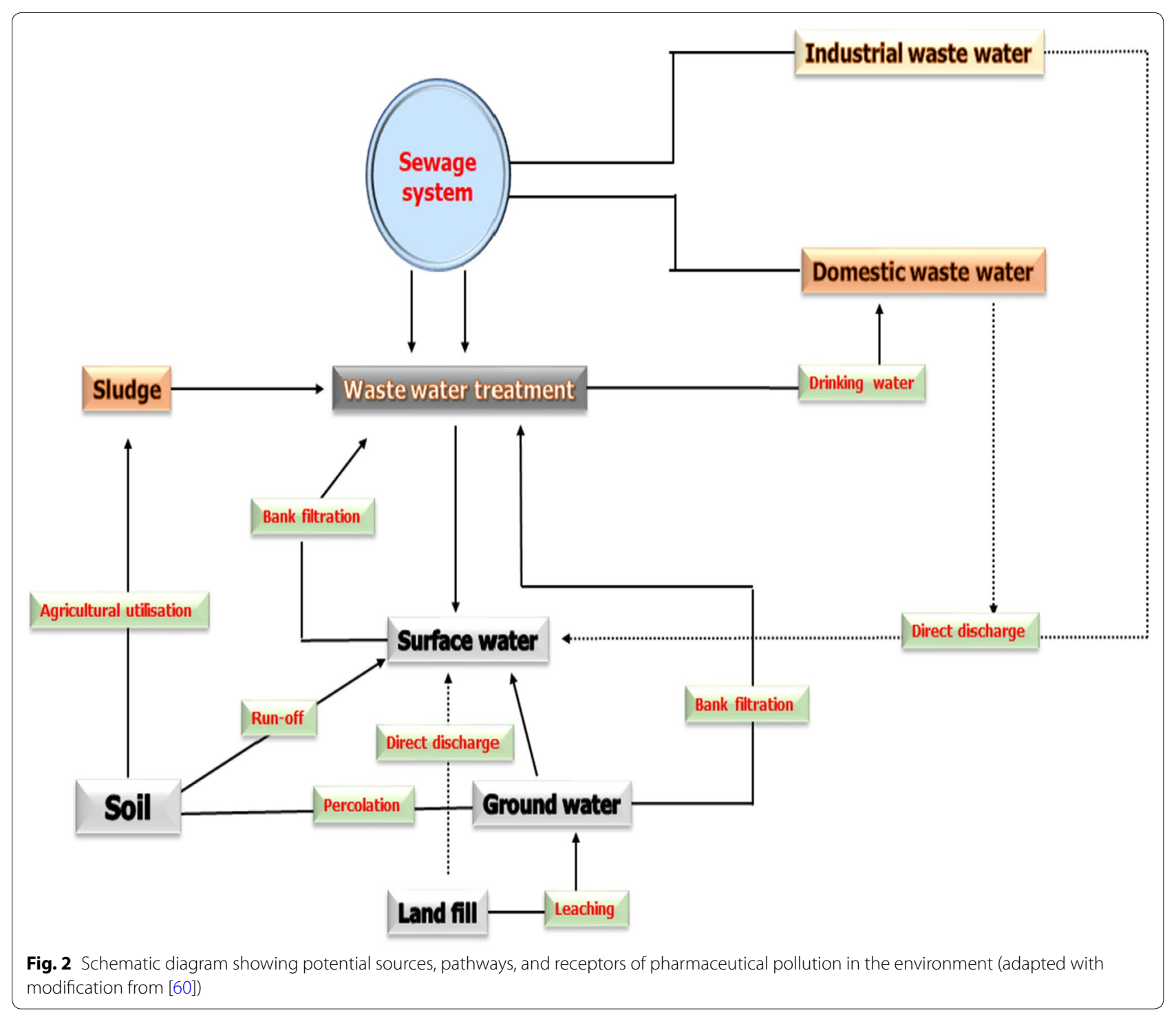

Kasprzyk-Hordern et al. [29] and Huerta-Fontela et al. [65] reported a concentration range of between 880 and $4026 \mathrm{ng} / \mathrm{L}$ for carbamazepine epoxide (a carbamazepine metabolite) in influents wastewater, while the concentration of its parent compounds (carbamazepine) range between $<1.5$ and $113 \mathrm{ng} / \mathrm{L}$. There is, therefore, a need to understand environmental transformation/metabolism, transformation products (metabolites), and analysis of pharmaceutical metabolites. This action is essential because of the expected time-bound decrease in the environmental concentration of parent compounds, with a corresponding increase in metabolites' level, as well as the potential of the metabolites, eliciting probably greater than parent compound adverse effects in the environment.

\section{Toxicity of pharmaceuticals and personal care products}

The benefits of the intended use of pharmaceuticals and many personal care products are enormous. The consumption of drugs evokes specific biological responses in the host, after which 10-90\% of excess unused doses and some conjugates metabolites are ultimately excreted and passed into the environment $[66,67]$. Their leak and presence in different environmental matrices could cause a risk on non-target organisms, mainly because of their weak degradation, persistence, and biological activities. Organisms within the aquatic and terrestrial environments have the potential to be most affected. Recent reports indicated that drinking water sources, especially those receiving water input from contaminated sources, 
contain residues of PPCPs, and thus may need further treatment to remove the pollutants before consumers supply [68].

There has been a growing concern about the environmental impact of pharmaceuticals and personal care products (PPCPs) in the aquatic environment [69] as a result of the fact that they can potentially elicit health and ecological impacts [55]. Furthermore, PPCPs may exist as mixtures with other contaminants in the environment and, therefore, can cause synergistic detrimental effects to both aquatic and terrestrial organisms even at low concentrations [70]. Antibiotics usage is common in animal husbandry for prevention, treatment, and growth purposes, making their over-use result in the genetic selection of more harmful bacteria [71]. Continuous exposure to antibiotics was noted as a probable cause of induced drug resistance in many pathogenic organisms, including bacteria.

Steroid hormones use as sex steroids, contraceptives, and birth control pills can interfere with the endocrine systems, or act as anti-androgenic ligands [72, 73]. Endocrine disruption leading to adverse effects such as sterilization, the imposition of sex organs (imposex), and feminization of some vertebrate, e.g., fish, mollusks, and other aquatic species have been reported [5, 74]. For instance, Solé et al. [75] reported that the presence of the hormone estrogen and progestogens at concentrations as low as approximately $1.0 \mu \mathrm{g} / \mathrm{L}$ caused endocrine-disrupting manifesting in fish feminization and decrease infertility. The accumulation of diclofenac on rainbow trout even at a low concentration of $5 \mu \mathrm{g} / \mathrm{L}$ had detrimental endocrine effects. In contrast, exposure to a mixture of acetaminophen, carbamazepine, gemfibrozil, and venlafaxine at concentrations between 0.5 and $10 \mu \mathrm{g} / \mathrm{L}$ was noted to cause effects such as tissue degeneration, a decline in embryo production and increase in embryo mortalities in zebrafish [76, 77]. Exposure to endocrine-disrupting contaminants in the aquatic environment was also reported to lead to the modulation of hypothalamus-pituitarygonad (HPG), hypothalamus-pituitary-thyroid (HPT) and hypothalamus-pituitary-adrenal (HPA), and resulting in the tampering of the activities and functions of various physiological traits in some non-target vertebrate aquatic organisms [78].

Drugs such as carbamazepine, levetiracetam, lamotrigine, and valproate used as antiepilepsy which have been detected in drinking water supply in South Africa was fingered to have the capacity to cause a number of several reproductive endocrine system side-effects in certain fish species as well as in humans [77, 79, 80]. NSAIDs like Naproxen and Ibuprofen that are often not resolved in WWTPs may also induce an adverse effect on the endocrine systems of non-target vertebrate organisms of WWTPs effluent receiving waters. For example, Japanese Medaka fish (Oryzias latipes) exposed to $0.1 \mu \mathrm{g} / \mathrm{L}$ concentration of Ibuprofen manifested delayed hatching while concentration reaching $1 \mathrm{mg} / \mathrm{L}$ in humans, can lead to an increase in blood plasma levels.

\section{Remediation, treatment, and removal of PPCPS from contaminated matrices}

Extraneous levels of widely distributed potentially toxics PPCPs and EDCs have been reported in many aqueous matrices worldwide. A large percentage of South Africa waters and aquatic ecosystem receives PPCPs contaminants via human excretions and improper discharge of pharmaceuticals into the sewage system [42, 81, 82]. Consequently, many non-target marine organisms have magnified drug residues to a varying extent in different organs of their bodies. PPCPs such as acetaminophen, caffeine, 1,7-dimethylxanthine, dehydronifedipine, tetracycline, oxytetracycline, sulfonamides, macrolides, and ormetoprim have been reported to be found in fruits, vegetables, fish, meat and even milk and dairy products as a result of uptake or exposure to PPCPs contaminated environment [83-85]. Thus, there is a need for the implementation of appropriate and effective environmental remediation to secure the health and safety of biological features, as well as environmental health and safety.

Several water treatment procedures and technologies have been developed and used for resolving contaminants in the environment, especially water and wastewater. The removal can be achieved through several processes, including; physical, biological, and chemical methods. The physical process may involve filtration where contaminants' removal is achieved by transforming one phase to another, leading to the production of highly concentrated sludge that could be toxic and more difficult to dispose of [86]. The biological process in water treatment revolves around aerobic and anaerobic degradation/digestion of nutrients and organics, while the chemical process is based on oxidative decomposition. However, many of these stepwise treatment techniques are insufficient, in that they are not able to remove or even degrade residues of PPCPs due to their deficient environmental concentrations, and because they were not initially factored in their design for such purposes [87]. Daughton and Ternes [44] reported that PPCPs are not entirely removed during wastewater treatment because the WWTPs are only designed to remove suspended solids, pathogens, and nutrients from wastewater using a serial link of processes to eliminate impurities, reduce nutrients and organic load and improve oxygen demand levels.

Petrović et al. [88], in a report, noted that the majority of the existing WWTPs are not designed to either treat or 
remove these contaminants and their metabolites. Ineffective treatment of wastewater has been listed as a significant source of PPCPs in many receiving fresh surface water systems and other aquatic environments, especially those freshwater systems used as domestic water sources. There is, therefore, a need for the development of more advanced, efficient, and powerful water and wastewater treatment technologies for the treatment of PPCPs contaminated water, wastewater/effluent from municipal and industrial wastewater discharge streams [89]. This measure is critical and very important in eliminating the potential toxicity and health implication that may arise as a result of exposure of aquatic organisms and possibly humans to these metabolites. The development of facile, cheap, and green methods that can be employed in the treatment of pollutants has been a significant area of research in the field of environmental science and technology. It is important to note that the ability of certain PPCPs to sorb onto bio-solids and siliceous solids, suspended solids confers the need for remediation of contaminated sediment as well as contaminated soil, where they may be ultimately sunk into, or be discharged onto via the application of bio-solids as manure on land.

\section{Water treatment and removal efficiency of PPCPs in WWTPs}

Over $80 \%$ of PPCPs are released into the environment from the human body in the parent form un-metabolized, i.e., without transformation [90]. These are fed through into the wastewater treatment plants for removal or decomposition during the water treatment process. Many WWTPs are, however, unable to wholly eliminate most PPCPs, hormones and their metabolites, resulting in their presence as residues in wastewaters, surface waters, sediments, and sludge. This inefficiency of WWTPs could be attributed to their conventional integrated treatment uses for biological treatment and microbial decomposition as a process for the breakdown of complex organics, nutrients, and activated sludge for the removal method of contaminants in water/wastewater. Unfortunately, residues of PPCPs, hormones, and their metabolites are not fully removed as the removal efficiency of most WWTPs ranged between 50 and $90 \%$ $[91,92]$. The removal efficiency of different PPCPs differs greatly, and varies with the physical and chemical properties of the parent compounds as well as the environmental conditions such as the configuration of biological reactors and operational parameters such as hydraulic retention time and sludge retention time $[93,94]$.

For example, carbamazepine, one of the contaminants that are most often detected in effluents, is known to be resistant to biodegradation, making it nearly impossible for efficient mineralization and removal in conventional biological treatment [20]. Wu et al. [95] reported that 23\% removal efficiency for carbamazepine after treatment of wastewater effluent in the conventional treatment process. The removal efficiency of other PPCPs such as ibuprofen, naproxen, ketoprofen, diclofenac, bezafibrate, sulfamethoxazole, and trimethoprim ranges from 60 to $100 \%$ [96-99]. The differences in the removal efficiency may be due to a number of factors, including the characteristic of the activated sludge, the concentration of the contaminants, the optimal operational condition of the WWTPs, and the water composition. Thus, the biological treatment process seems to be economically feasible and widely applicable but not effective in degrading many organic pollutants.

Most WWTPs utilizes various method in the conventional treatment systems for the removal of PPCPs such as coagulation, flocculation, and sedimentation of raw sewage, activated sludge, membrane bioreactor, sequential batch reactor up-flow anaerobic sludge blanket processes $[100,101]$. Some treatment methods are, however, more efficient and effective in removing pharmaceuticals compounds of interest, compared to another. This might be as a result of the physicochemical properties, the hydrophobicity, and biodegradability of target pharmaceuticals and process operating parameters in the WWTPs [102]. For instance, Berset et al. [103] reported that using the conventional methods involving dioxychlorination and sand filtration processes, cocaine and benzoylecgonine were poorly removed, while they were removed entirely when ozonation process was used. Nonsteroidal anti-inflammatory drug removal in WWTPs are achieved to a different extent. Upon treatment with a mixture of dioxychlorination and sand filtration, diclofenac (over 99\%) was almost completely removed; naproxen was moderately removed (48\%), while ibuprofen was poorly removed (14\%). When ozonation process was used as a treatment process, more than $40 \%$ ibuprofen, naproxen, and diclofenac were removed by less than $20 \%$, while dioxychlorination and sand filtration process remove sulfonamides and macrolides efficiently [104]. Thermal destruction of pollutants at high temperatures is also a suggested elimination procedure. However, this technique may lead to undesirable emissions and damage to useful microbes and aquatic life forms, while it is not economically feasible.

\section{Biosorptive method for the removal of PPCPs from contaminated water}

Wastewater treatment plants (WWTPs) rely on biodegradation and adsorption methods using conventional adsorbents such as activated sludge for removal of contaminating substances in aqueous matrices, but their use is limited. This limitation is because their removal 
efficiency changes significantly, and varies with the physicochemical properties of the compounds as well as the environmental conditions and operational parameters $[58,105]$. The biological, chemical, and physical processes have been studied for the removal of PPCPs from contaminated matrices [106]. Among these techniques, biosorptive method is seen as one of the environmentally friendly techniques used in the removal of PPCPs from aqueous solutions. Bioadsorptive immobilization have been reported to show promising results for the removal of some organic contaminants in laboratory pilot-scale experiments while biodegradation was proven to be inefficient for the removal of PPCPs due to poor degradability and low environmental concentration [107, 108].

Biosorptive processes have the advantages of effectiveness, simplicity, low cost, and sustainability [58]. Despite these advantages, the efficiency of bio-adsorption varies depending on the characteristics, polarity, the activity of the sorbent materials, the chemical properties and behaviours of the adsorbate material, thus suggesting incomplete pollutant removal and thereby passing them out in WWTP effluent. The cost of WWTP operation due to high energy requirements and low output is also a limitation [89]. There is also a tendency of the transformation of some non-biodegradable contaminants into toxic contaminants that can exert toxicity to micro-organisms under the treatment conditions [109].

Commercial activated carbon as absorbents is one of the most widely studied materials for the removal of organic pollutants. Still, its drawback is in the high manufacturing cost and the deficiency of regeneration. Hence the preparation of economical adsorbents from agricultural waste, clay materials, biomass, non-living algae, and seafood-processing waste products, which are cheap, have been employed as biosorptive material for the removal of numerous organic pollutants from different water matrices [110]. Li et al. [111] reported the high removal efficiencies of diclofenac and trimethoprim via the use of agro-waste materials such as biochar, macroalgae, and wood chipping. These biosorptive materials indicated possible high removal at low concentrations, thereby offering a clean, sustainable, and practical water treatment solution for purifying water.

Alkaline-modified biomass employed for the removal of tramadol achieved a $91 \%$ removal at $\mathrm{pH}$ of 7 , biosorbent dose of $0.5 \mathrm{~g} / \mathrm{L}$, and $50 \mathrm{mg} / \mathrm{L}$ contaminant concentration load of tramadol within $45 \mathrm{~min}$. The removal efficiency of the sorbent was possible because of the hydrophilic interaction between amino and carbonyl groups within the pharmaceuticals moieties, and the hydroxyl and carbonyl functional groups generated on the surface of the modified algal biomass [110]. Moreover, different biosorbents such as graphene oxide and carbon nanotubes have been used in the removal of various pharmaceuticals and personal care products [112-114]. Solution pH, temperature, interfering substances, ionic strengths of the matrix are among the environmental factors that play an essential role during biosorptive process for the removal of PPCP. However, their inability to be able to remove a large number of pharmaceuticals from wastewater treatment plants efficiently calls for the development of an efficient technology with acceptable cost and effective for mineralization of pharmaceuticals from the wastewater treatment plants.

\section{Chemical oxidation methods for the dissipation and mineralization of PPCPs in water}

Chemical oxidation method offers a better technology in that the challenges associated with the use of conventional wastewater treatment plants, which include incomplete degradation of organic pollutants, sludge formation, the formation of secondary pollutants, and high cost, are eliminated. Chemical oxidation generally overcomes the limitations of other treatment processes, although it may not result in the complete mineralization of the organic pollutants [115]. Chemical oxidation, often referred to as an AOP, involves the use of oxidants like ozone, hydrogen peroxide, and chlorine.

Chemical treatment method involving advanced oxidation processes such as ozonation, peroxidation, ultraviolet light aided ozonation $\left(\mathrm{O}_{3} / \mathrm{UV}\right)$, ultraviolet light aided peroxidation $\left(\mathrm{UV} / \mathrm{H}_{2} \mathrm{O}_{2}\right)$, Fenton and Fenton-like oxidation, gamma radiolysis, sonolysis as well as electrochemical oxidation process have been reported to be sufficient for the degradation of toxic pollutants in the aqueous matrices [116]. Howbeit, the advanced oxidation process methods have been associated with the disadvantage of high energy demand for various critical devices such as ozonizers, UV lamps, and ultrasonicators, and this leads to high operation costs [117].

Basically, advanced oxidation processes rely on in situ generation of highly potent chemical oxidants in the presence of ozone $\left(\mathrm{O}_{3}\right)$ or hydrogen peroxide $\left(\mathrm{H}_{2} \mathrm{O}_{2}\right)$ and the presence of a catalyst such as the Fenton's reagent or UV light [118]. AOPs uses reactive species such as the hydroxyl radicals $\mathrm{OH}$. generated in sufficient quantity for water purification, in which both organic and inorganic pollutants are removed through $\mathrm{O}_{3}$ aided oxidation or $\mathrm{H}_{2} \mathrm{O}_{2}$ supported oxidation, in the presence of catalysts such as $\mathrm{TiO}_{2}, \mathrm{ZnO}, \mathrm{BiO}_{2}, \mathrm{CuO}$ etc., and UV light as an energy source at ambient temperature and pressure [119]. AOPs are classified into two based on photondriven reactions;

a. Photochemical processes such as UV oxidation, UV/ $\mathrm{H}_{2} \mathrm{O}_{2}, \mathrm{UV} / \mathrm{O}_{3}, \mathrm{UV} / \mathrm{H}_{2} \mathrm{O}_{2} / \mathrm{O}_{3}$, UV/Ultrasound, Photo- 
Fenton, photocatalysis, sonophotocatalysis, vacuum UV, microwave, and,

b. Non-photochemical processes such as ozonation, ultrasound, $\mathrm{US} / \mathrm{H}_{2} \mathrm{O}_{2}, \mathrm{US} / \mathrm{O}_{3}$, US/Fenton, electrochemical oxidation, supercritical water oxidation, ionization radiation, electron-beam irradiation, wetair oxidation [120].

AOPs excel overall biological and chemical processes in that they are environmentally friendly as they are known not to transfer pollutants from one phase to the other, as seen during chemical precipitation, adsorption, and volatilization [120]. Moreover, they do not produce a large quantity of poisonous sludge during activated sludge processes as with other treatment methods. Popular advanced oxidation processes used for the removal of contaminants include $\mathrm{TiO}_{2}$ and photo-fenton processes. Generally, photocatalyzed AOP is environmentally benign, biocompatible, highly stable with low-cost metal oxide photocatalyst (such as $\mathrm{TiO}_{2}$ ), and can efficiently be used to remove different organic pollutants from water matrices $[121,122]$. The photocatalytic degradation of organic pollutants within the water matrices are very efficient and effective due to the following factors; (i) good operating conditions at ambient temperature and pressure, (ii) complete mineralization of substrate and intermediate into $\mathrm{CO}_{2}$ and $\mathrm{H}_{2} \mathrm{O}$, (iii) no problem with disposing of solid waste, (iv) utilization of sunlight, near UV-light or visible light for irradiation, (v) formation of non-toxic by-products and (vi) low cost $[12,123]$.

$\mathrm{TiO}_{2}$ photocatalysis, however, offers better activity during the removal of organic pollutants because of their heterogeneous nature, hence, the possibility of catalyst reuse and their operation at a wide $\mathrm{pH}$ range when compared to photo-fenton process. Although different AOPs method has been employed in the degradation of PPCPs, however, this review intends to emphasize on the catalytic activity of semiconducting photocatalyst doped on solid supports such as activated carbon, carbon nanotubes, and graphene oxides and their application in the degradation of PPCPs. One of such semiconducting photocatalyst is $\mathrm{TiO}_{2}$, or $\mathrm{TiO}_{2}$ immobilized on other solid materials used in AOPs processes. Photocatalysis occurs upon the absorption of ultraviolet, visible, or infrared radiation by the photocatalyst in such a way that results in a change in the rate of the chemical reaction. The use of catalysts such as $\mathrm{TiO}_{2}$ or $\mathrm{TiO}_{2}$ immobilized on a support material was reported to lead to improved oxidation under solar irradiation, while the radiation also serves as a more sustained and energy-efficient solution for degradation of organic contaminants in the aqueous environment $[124,125]$.
Photocatalysis can either be a homogenous or heterogeneous photocatalyst. Homogenous photocatalysis occurs when both the photocatalyst and the organic pollutants are soluble and exist in the same phase during the photocatalytic process. An example of homogenous photocatalyzed AOP is the photo-Fenton process, which involves the iron salt catalyzed $\mathrm{H}_{2} \mathrm{O}_{2}$ reaction in the presence of UV-visible radiation as an energy source used for the generation of hydroxyl radicals as shown in the reaction below [126].

$$
\begin{aligned}
& \mathrm{Fe}^{2+}+\mathrm{H}_{2} \mathrm{O}_{2} \rightarrow \mathrm{Fe}^{3+}+\mathrm{OH}^{-}+\mathrm{OH}^{\cdot} \\
& \mathrm{Fe}^{3+}+\mathrm{H}_{2} \mathrm{O}_{2} \rightarrow \mathrm{Fe}^{2+}+\mathrm{HO}^{2 \cdot}+\mathrm{H}^{+} \\
& \mathrm{Fe}^{3+}+\mathrm{HO}^{2 \cdot} \rightarrow \mathrm{Fe}^{2+}+\mathrm{O}_{2}+\mathrm{H}^{+} \\
& \mathrm{Fe}^{3+}+\mathrm{H}_{2} \mathrm{O}+h v \rightarrow \mathrm{Fe}^{2+}+\mathrm{H}^{+}+\mathrm{OH}^{\cdot}
\end{aligned}
$$

This process is used in the degradation of pharmaceuticals as a result of its simplicity and easy reactor design. Photo-Fenton processes have been applied for the degradation of organics pollutants in different environmental matrices. de Luna et al. [127] reported the degradation of acetaminophen by Fenton oxidation in a fluidizedbed reactor where the effect of operating parameters such as $\mathrm{pH}$, temperature, the concentration of $\mathrm{H}_{2} \mathrm{O}_{2}$ and $\mathrm{Fe}^{2+}$ were monitored for the pseudo-second-order kinetic degradation $99.6 \%$ of the organic substrate. The Fenton process has also been proven to be a viable catalyst for photo-degradation of pharmaceuticals such as hydrocortisone, estradiol, and verapamil. The reaction mixture containing ferric ions as catalyst showed 100\% degradation of the three pharmaceuticals in less than $1 \mathrm{~h}$, compared to the use of $\mathrm{TiO}_{2}$ in a heterogeneous photocatalyzed process which shows a more favorable level of mineralization which in turn prevent the danger involved in the accumulation of harmful organic pollutants in the water body [128].

The drawbacks in the use of this process include the use of reagents, strict $\mathrm{pH}$ control due to the process's $\mathrm{pH}$ dependence, and the formation of sludge. To overcome these challenges, the development of heterogeneous catalysts for the oxidation degradation processes was crucial, due to their potential role in facilitating the degradation and complete mineralization of organic contaminants, especially PPCPs. Current heterogeneous catalyst development studies are directed towards improving the synthesis, and functionality of various sizes and shapes of metal nanoparticles semiconducting photocatalyst, aimed at improving the performance and utilization of nanoparticles in multiple applications, including advanced oxidation processes (AOPs). In general, the use 
of ozonolysis and photocatalytic oxidation has proven to be promising as pre-treatment/treatment techniques for the mineralization of organic pollutants when compared with other chemical oxidation processes.

\section{Ozonolysis processes}

The ozonolysis process is an advanced oxidation process that is based on the synergistic interaction between an oxidant such as ozone or abundant oxygen. Ozonolysis may be supported by catalyst or radiation or a combination of both resulting in the generation of hydroxyl radicals (HO-), which is a short-lived oxidizing species that reacts with both organic and inorganic pollutants within the water matrices in a non-selective manner [129]. Due to AOPs ability for selective degradation of recalcitrant organic pollutants, they may function as a pretreatment process prior to biological treatment techniques, thus suggesting integrated treatment as a more efficient and effective means for the removal of organic pollutants from highly contaminated wastewater $[130,131]$.

The preference for the use of ozonolysis in the removal of pollutants is because they do not cause a significant increase in salt concentration. It leaves no presence of chemical residue after usage, as observed with waste activated sludge, where bio-recalcitrant components and low soluble volatile organic compounds, are partially oxidized and solubilized to produce a biodegradable product [132, 133]. However, this method is expensive and requires a high operating cost, thereby making its application for pollutants removal limited. The technique is also associated with the generation of intermediates, which could be challenging to eliminate.

\section{AOP using heterogeneous photocatalysts}

This process is made up of purely chemical and physical reaction routes in which the photocatalyst is generated and its activity maintained by the absorption of radiant energy [134]. Heterogeneous photocatalysis occurs when the activity of semiconducting photocatalyst, which in most cases is insoluble in the solution that contains the organic substrates, and dependent on the $\mathrm{pH}$ of the solution, is initiated by the absorption of radiant energy. The generated photon with energy band gap level equal to or greater than the band gap energy of the photocatalyst which is the difference between the energy of the valence band full of electrons and that of the conduction band that is empty. Then, mobile electrons can access the conduction band, leaving positive holes in the valence band $[131,135]$. Hence the catalyst and the substrates exist in different phases. The heterogeneous nature of the oxidative reaction makes for easy and cheap recovery catalyst from the solution after use.
The conventional semiconducting nanoparticles used in AOPs for the treatment of organic pollutants in water matrices include $\mathrm{TiO}_{2}$ in homogenously catalyzed process, while those use as heterogeneous catalysts; $\mathrm{ZnO}$, $\mathrm{SnO}_{2}, \mathrm{Al}_{2} \mathrm{O}_{3}, \mathrm{In}_{2} \mathrm{O}_{3}, \mathrm{ZnS}, \mathrm{Fe}_{2} \mathrm{O}_{3}, \mathrm{CeO}_{2}, \mathrm{ZrO}_{2}, \mathrm{SiO}_{2}, \mathrm{CuO}$, $\mathrm{MnO}_{2}$ and $\mathrm{CdS}$ which function as sensitizers for lightinduced redox processes. The $\mathrm{TiO}_{2}$ photocatalytic process leverage via direct photolysis of photon energy from UV and photocatalysis by producing hydroxyl radicals where $\mathrm{TiO}_{2}$ is photo-activated to generate hydroxyl radicals on the surface of the crystal before reaction with a wide range of organic pollutants which in turn lead to mineralization of the pollutants to $\mathrm{CO}_{2}$ and $\mathrm{H}_{2} \mathrm{O} \mathrm{UV}$ radiation $[125,136]$. The continuous design and development of various photocatalyst by researchers around the world affirmed that heterogeneous photocatalysis presents the best technological opportunities for the degradation of organic pollutants within the environment.

\section{Nanomaterial as photocatalyst in the degradation of PPCPs in WWTPs}

Nanoparticle photocatalytic reactions can be described as the interaction of light energy with a metallic nanoparticle. This process is used in wastewater treatment as a result of their broad and high photocatalytic activities on the decomposition of various organic pollutants [137]. Nano-photocatalysts consist of nano-size order metal oxides, with semiconducting properties and strong ability to degrade large varieties of persistent organic pollutants such as dyes, detergents, pesticides, and volatile organic compound that WWTPs cannot remove [138, 139]. Quite several semiconductors such as $\mathrm{ZnO}, \mathrm{SrTiO}_{3}$, $\mathrm{Fe}_{2} \mathrm{O}_{3}, \mathrm{SnO}_{2}, \mathrm{CuO}_{2}, \mathrm{WO}_{3}$, and $\mathrm{Fe}_{3} \mathrm{O}_{4}$ have been used for the decomposition of organic pollutants from different environmental matrices [139-141]. They can also be used for degrading halogenated and non-halogenated organic compounds, PPCPs, and heavy metals in some specific situations [7].

\section{Photocatalyst and photocatalytic method in advance oxidation procedures}

The photocatalytic method is a promising technology used in the treatment of contaminants as a result of the ability of the catalyst to use sunlight as the energy source to initiate and facilitate the degradation of organic pollutants [142]. However, some of the challenges encountered with the use of photosensitive semiconductors as catalysts are low quantum efficiency, rapid recombination of photogenerated carriers, narrow optical response, and a slow transfer rate of electrons to oxygen which hinder their applications in the treatment of organic pollutants [143]. These limitations could be eliminated by employing strategies such as the modification of the textural 
properties, heterojunction construction, elemental doping, and morphology control to improve their photocatalytic performance [141].

The modification of photocatalysts that are highly active via visible light enhances the central part of the solar spectrum to be used. Therefore, to exploit the visible light during the photocatalytic process, there is a need for the usage of narrow band gap semiconductors like $\mathrm{Cu}_{2} \mathrm{O}, \mathrm{WO}_{3}, \mathrm{CdS}, \mathrm{BiVO}_{4}$ etc., for the degradation of different organic pollutants. Cheng et al. [144] reported the photocatalytic activity of $\mathrm{Cu}_{2} \mathrm{O}-\mathrm{Cu}$ composites irradiated under visible light at $420 \mathrm{~nm}$ for the degradation of methylene blue, where $52 \%$ removal was achieved after $60 \mathrm{~min}$. The intensity degraded after irradiation at $664 \mathrm{~nm}$ as observed by the disappearance of its peak after $60 \mathrm{~min}$. Li et al. [145] synthesized Z-scheme heterostructure nanocomposites by loading mesoporous $\gamma-\mathrm{Fe}_{2} \mathrm{O}_{3}$ nanosphere on $\mathrm{g}-\mathrm{C}_{3} \mathrm{~N}_{4}$ nanosheet, the synthesized Z-scheme $\gamma-\mathrm{Fe}_{2} \mathrm{O}_{3} / \mathrm{g}-\mathrm{C}_{3} \mathrm{~N}_{4}$ heterostructure exhibits mesoporous features with the improved specific surface area providing reactive mass sites for tetracycline; also the constructed heterostructure which existed between $\gamma-\mathrm{Fe}_{2} \mathrm{O}_{3}$ and $\mathrm{g}-\mathrm{C}_{3} \mathrm{~N}_{4}$ efficiently extends the response range which leads to the quick transfer and separation of photoinduced charge carrier which enhances its photocatalytic activity for mineralization of tetracycline hydrochloride under visible light irradiation.

The working mechanisms behind the photo-catalyzed advanced oxidation process are based on the photoexcitation of electron in the catalyst. For instance, if photocatalyst, such as $\mathrm{TiO}_{2}$, is irradiated with UV light, it causes a generation of holes $\left(\mathrm{h}^{+}\right)$and exits electron $\left(\mathrm{e}^{-}\right)$ in the conduction band. In aqueous media, there is an entrapment of water molecules $\left(\mathrm{H}_{2} \mathrm{O}\right)$ onto the holes $\left(\mathrm{h}^{+}\right)$, leading to the generation of hydroxyl radicals $(\cdot \mathrm{OH})$. These hydroxyl radicals are indiscriminate, highly reactive, non-selective, and powerful oxidizing agents, which in turn, oxidize organic pollutants into water and gaseous degradation products [137].

\section{$\mathrm{TiO}_{2}$ photodegradation process}

$\mathrm{TiO}_{2}$ stands out as an excellent photocatalyst amongst the semiconductors that can be used for the degradation of PPCPs, due to its optical and electronic features, photosensitivity, physical and chemical stability, costeffectiveness, resistance to light corrosion, non-toxicity and their high accessibility [146, 147]. Polymorphs of $\mathrm{TiO}_{2}$ include anatase, rutile, and brookite [148], of which anatase $\mathrm{TiO}_{2}$ have been shown to exhibit the highest photocatalytic activity as a result of the extended lifetime of the photoexcited electrons, and the fast migration of photogenerated electrons [149].
Literature reports indicated that the photocatalytic degradation of PPCPs using $\mathrm{TiO}_{2}$ as catalysts could result in mineralization reaching close to $99 \%$ within 1 to $3 \mathrm{~h}$ under various parameters. For example, the photocatalytic degradation of ofloxacin and atenolol irradiated under a UV lamp was almost complete after $240 \mathrm{~min}$ [60, 150]. Furthermore, photocatalytic mineralization of tetracyclines, paracetamol, caffeine, and atenolol as single/lone pollutants and in mixtures was achieved via $\mathrm{TiO}_{2}$ irradiated under UV and simulated solar irradiation, where the removal of tetracyclines reaches $90 \%$ after $35 \mathrm{~min}$ and that of paracetamol, caffeine, and atenolol were between 80 and $90 \%$ after $6 \mathrm{~h}$, while the degradation of the mixture of these pharmaceuticals was achieved at $60 \%$ after $6 \mathrm{~h}$ under the same conditions [151]. He et al. [152] reported that $100 \%, 100 \%, 76 \%$, and $74 \%$ photocatalytic degradation of propranolol, diclofenac, carbamazepine, and ibuprofen, respectively, was achieved after $96 \mathrm{~h}$ via the immobilization of $\mathrm{TiO}_{2}$ on the sand. The degradations were made possible as a result of the photo-oxidation of substrates from the single oxygen generated in the reaction mixture [153].

Considerable removal performance can be achieved in the presence of simulated solar light. Irradiated $\mathrm{TiO}_{2}$ was also applied for the mineralization of organic molecules such as acetylene in the gas phase. Acetylene mineralization/degradation in the gas phase follows a first-order kinetic in which no organic intermediate was detectable, suggesting that no pollutants or any intermediate species interfere in the photocatalytic mineralization [154]. However, the usage of $\mathrm{TiO}_{2}$ as a photocatalyst has critical limitations such as its wide intrinsic band gap that is $3.0 \mathrm{eV}$ and $3.3 \mathrm{eV}$ for rutile and anatase, respectively, and this results in achieving an activation at ultraviolet radiation at $\lambda<380 \mathrm{~nm}$. This wide band gap can be reduced via doping of $\mathrm{TiO}_{2}$, in order to cause a shift in absorption in the visible light region of $\lambda>400 \mathrm{~nm}[116,155]$. Another challenge of $\mathrm{TiO}_{2}$ as a conventional powdered catalyst for photodegradation is the difficulty of their separation from the slurry of the reactor systems after photocatalysis, and this leads to low efficiency in photocatalytic activities over a range of application $[125,156]$.

Due to surface limitations and inadequate adsorption capacity of $\mathrm{TiO}_{2}$ resulting from non-porous nature, current studies are directed towards incorporating photocatalysts on porous supports in order to facilitate the efficient absorption of target environmental pollutants prior to subsequent oxidation aided by the photocatalyst. To achieve a more rapid and efficient removal of PPCPs in WWTPs, there is a need to modify the photocatalytic process through immobilization of $\mathrm{TiO}_{2}$ onto a suitable solid support such as activated carbon, molecular sieve, graphene, and minerals as a result of their ability to 
enrich the pollutants and improves their photocatalytic degradation rate due to its stability, mechanical resistance, high surface area and appropriate porosity [157, 158].

\section{ZnO photodegradation process}

$\mathrm{ZnO}$, with strong oxidation ability and a tremendous photocatalytic property, has also been used in the degradation of various organic pollutants due to its direct and broad band-gap energy close to UV spectral region, hence their thermal stability and considerable free-exciton binding energy. It is also relatively cheap when compared to $\mathrm{TiO}_{2}$, which is said to be non-economical for the treatment of water on a large scale $[159,160]$. $\mathrm{ZnO}$ nanoparticles have been reported to be more catalytically active compared to $\mathrm{TiO}_{2}$ for degradation of pharmaceuticals, where the photocatalytic degradation of 14 pharmaceuticals was studied using $\mathrm{ZnO}$ and $\mathrm{TiO}_{2}$ nanoparticles [161]. Study results showed that 95\% removal was achieved after 40 min under UVA irradiation via $\mathrm{ZnO}$ nanoparticles catalyzed process, whereas only $40 \%$ removal was achieved for $\mathrm{TiO}_{2}$ catalyzed process under the same condition. The photocatalytic activities of different types of $\mathrm{ZnO}$ were studied for the degradation of methylene blue, where the reaction was monitored at $\mathrm{pH} 7.5$ for $60 \mathrm{~min}$ under UV irradiation of $664 \mathrm{~nm}$. $\mathrm{ZnO}$ nanofibers were noted to be the best among the fabricated $\mathrm{ZnO}$, as photo-degradation reaches almost $100 \%$ for methylene blue removal [160]. The photocatalytic efficiency of $\mathrm{ZnO} / \mathrm{g}-\mathrm{C}_{3} \mathrm{~N}_{4}$ composites was investigated by Ismael [162] for the degradation of methyl orange and 4-chlorophenol under visible light radiation. Its photocatalytic performance was due to the synergistic effects between $\mathrm{ZnO}$ and $\mathrm{g}_{-} \mathrm{C}_{3} \mathrm{~N}_{4}$, resulting in the interfacial transfer of photogenerated electrons and holes hence its effective charge separation resulting in their ability to be able to degrade methyl orange and 4-chlorophenol.

\section{$\mathrm{WO}_{3}$ photodegradation process}

Another semiconductor which has been used in the photocatalytic degradation of organic pollutants is $\mathrm{WO}_{3}$ $\mathrm{WO}_{3}$ is an n-type semiconductor with high stability and a wide tunable band gap of around $2.6 \mathrm{eV}$, hence their application in the photocatalytic degradation of various organic pollutants. For instance, complete degradation of rhodamine $\mathrm{B}$ was achieved when $\mathrm{WO}_{3}$ nanoplatelet was employed, with the intensity peak of Rhb disappearing after $350 \mathrm{~min}$, when the catalyst reacted with the organic pollutants to form an unstable intermediate under UV light irradiated at $554 \mathrm{~nm}$ [163]. Chen et al. [164] reported the fabrication of $\mathrm{WO}_{3} / \mathrm{g}-\mathrm{C}_{3} \mathrm{~N}_{4}$ nanocomposites by a simple direct precipitation method, and the Z-scheme photocatalyst $\mathrm{WO}_{3} / \mathrm{g}-\mathrm{C}_{3} \mathrm{~N}_{4}$ was designed and prepared by dispersing $\mathrm{WO}_{3}$ nanosheets on $\mathrm{g}-\mathrm{C}_{3} \mathrm{~N}_{4}$ nanosheets. The as-prepared $\mathrm{WO}_{3} / \mathrm{g}-\mathrm{C}_{3} \mathrm{~N}_{4}$ showed enhanced photocatalytic activity toward degrading methyl orange. The improved photocatalytic performance of $\mathrm{WO}_{3}$ nanosheet doped on $\mathrm{g}-\mathrm{C}_{3} \mathrm{~N}_{4}$ was due to the coupling of effect of $\mathrm{g}-\mathrm{C}_{3} \mathrm{~N}_{4}$ on $\mathrm{WO}_{3}$ resulting in a slight shifts to lower binding energy, which hints the strong interaction between $\mathrm{WO}_{3}$ and g- $\mathrm{C}_{3} \mathrm{~N}_{4}$.

\section{$\mathrm{Ag} / \mathrm{AgCl} / \mathrm{AC}$ photodegradation process}

Photocatalytic degradation involving tetracyclines reaches $97.3 \%$ in 60 min under visible light radiation through the use of $\mathrm{Ag} / \mathrm{AgCl} / \mathrm{AC}$ composites. The reactive species that aided the degradation are electron holes and superoxide radicals, while the exposed activated carbon surface in the composites photocatalyst enhances the tetracyclines adsorption onto its surface, thereby increasing the contact sites between tetracycline and photocatalyst which lead to a better and efficient photodegradation rate [165].

\section{Carbon-solid supports in photocatalytic degradation}

The photocatalytic performance of various photocatalysts has been mostly enhanced for the degradation of organic pollutants by combining them with carbonaceous materials. These carbonaceous materials, when compared to single semiconductors, give additional advantages such as chemical stability, thermal stability, high surface area, pore structure, good conductivity, excellent electronic properties, better photocatalytic activity, activity under solar irradiation and easy separation [106]. Activated carbon (AC), carbon nanotubes CNTs) and graphene are among the best solid materials for use as catalyst support for photocatalytic purposes, especially those use for the degradation of PPCPs in water and wastewater, due to properties such as; large specific surface areas and high charge carrier mobility [166, 167]. Activated carbon is porous and amorphous solid carbon material that can be derived from coal or plants through carbonization at a temperature between 400 and $600{ }^{\circ} \mathrm{C}$, with an activation process by use of steam or $\mathrm{CO}_{2}$ [168]. Activated carbon is non-photocatalytic in nature but can serve as a means to enhance the photocatalytic reaction between catalyst, e.g., $\mathrm{TiO}_{2}$ and the organic contaminants, by adsorption of pollutants on its surface to facilitate the degradation of organic contaminants [169].

The use of carbonaceous material in the degradation of PPCPs has been studied several times, and it has been proven that they can only adsorb pollutants, but cannot transform them, thus leading to the generation of hazardous products. In a situation where the adsorbents were not regenerated on-site, such adsorbents become 
hazardous waste and must be disposed of carefully, coming with additional cost. The use of carbonaceous material can, therefore, be expensive [7]. The affinity of solid materials for PPCPs results from the presence of functional groups such as carboxyl, carbonyl, phenol, lactone and quinone, which confers on them surface-active species and specific surface areas that attract solid materials and concentrating them close to the semiconducting active site for improved photodegradation [170]. This makes the composites serve as effective adsorbent material due to one or more combinations of either hydrophobic interaction, $\pi-\pi$ interaction, hydrogen bonding interactions, and electrostatic and dispersion interaction [171]. The clogging of the pore on adsorbent material is also a common challenge.

\section{Activated carbon (AC) for photocatalytic degradation}

Carbonaceous materials like activated carbon function as electron scavenger because of their enormous electron storage ability, which is known as Hoffman mechanism property [172]. They also act as a sensitizer-providing electron for semiconductor photocatalyst such as $\mathrm{TiO}_{2}$, g- $\mathrm{C}_{3} \mathrm{~N}_{4}$, etc. The electrons are excited by photons of light energy, which produces the superoxide radicals from absorbed molecular oxygen. Moreover, the positively charged composite material attracts electron from semiconducting metal catalysts such as $\mathrm{TiO}_{2}$, to create a hole $\left(h^{+}\right)$which interact with adsorbed water to generate hydroxyl radicals, in the $\mathrm{TiO}_{2}$ valence band. The presence of carbon-oxygen-titanium linkages within the composite materials leads to a reduction in the band gap and extends the absorption band into the lower energy visible range [116]. Moreover, the interest in the use of activated carbon as solid support for various photocatalyst semiconductor is as a result of its developed pore structures, very large surface area and high adsorption capacity, hence their usage as an adsorbent for both organic and inorganic pollutants [173].

Activated carbon in the $\mathrm{TiO}_{2}$ immobilized on activated carbon photocatalyst, serves as a reaction medium through which organic molecules are absorbed before degradation [174]. The complete removal of pharmaceuticals such as amoxicillin, ampicillin, acetaminophen, and diclofenac was achieved using $\mathrm{AC}-\mathrm{TiO}_{2}$ composite material under sunlight irradiation for $180 \mathrm{~min}$, and this cannot be achieved with bare $\mathrm{TiO}_{2}$ [173]. This is a result of the transfer of sorbate from activated carbon to photoactive $\mathrm{TiO}_{2}$ due to the presence of a common interface between them [167]. Another solid support that has been of great use owing to its high surface area, chemical and thermal stability is zeolite [175]. Their immobilization on $\mathrm{TiO}_{2}$ has proven to be efficient in the removal of highly volatile organic contaminants due to their adsorptive nature, and this can easily be supplied onto the $\mathrm{TiO}_{2}$ photocatalyst surface [176]. Bare $\mathrm{TiO}_{2}$ samples can rapidly deteriorate, while $\mathrm{TiO}_{2}$ composites can maintain a high adsorption efficiency to remove organic contaminants over a long period [177].

\section{Preparation of activated carbon and the fabrication of doped activated carbon}

Khraisheh et al. [178] reported the preparation of activated carbon from coconut shell material, which is an inexpensive source of carbon. AC prepared from many other biomass materials including, plant remains, animal remains, agricultural wastes, decomposing materials, etc., have been reported [179-181]. Carbon sources for the preparation of activated carbon vary from chemical to biological/natural sources, while the method of preparation depends on the nature and characteristics of the carbon source. However, production using biological/natural material sources are relatively cheaper than chemical raw materials because the organic/natural sources are often waste materials, hence the need for the use of plant material as a source for activated carbon.

This technique is followed by the immobilization/ doping of activated carbon with a metal oxide or nano metal oxides to form a composite catalyst. Different physical and chemical characteristics and attributes are achieved depending on how and which method is used for activated carbon preparation and how the metal oxide is doped/immobilized on the ACs. Arana et al. [182] reported that the reaction of $\mathrm{TiO}_{2}$ with activated carbon at different proportions showed that activated carbon not only increase the surface area but there is a modification of the acid-base properties and the UV spectrum of $\mathrm{TiO}_{2}$. The following methods have been used in the preparation of $\mathrm{AC}$ as a carbon source for photocatalytic degradation of organic pollutants: sol-gel, chemical vapor deposition, impregnation, pyrolysis, precipitation, hydrothermal preparation, microwave-assisted synthesis and sonochemical treatment [183-185].

The mostly used among the above method is the sol-gel method because there is an ultimate mixing or chemical interaction between activated carbon and the corresponding semiconductor photocatalyst. Studies proved that doped/immobilized metal oxides composite material possess superior quality and has the highest removal efficiency under UVC intensity. In $\mathrm{TiO}_{2}$ composite material, for example, the composite solid support doped with $\mathrm{TiO}_{2}$ showed higher photocatalytic activity, adsorption capacity, electron scavenging, and sensitization ability and extended visible light adsorption when compared to bare $\mathrm{TiO}_{2}$ [186]. The photocatalytic activity of prepared nanocomposite $\mathrm{ZnO} / \mathrm{AC}$ where the activated carbon was prepared from biomass degrades more than 
95\% organic pollutants as a result of the addition of electrolyte, although this decreases the photoactivity of the catalyst [187].

\section{Carbon nanotubes doped composites in photodegradation} Carbon nanotubes are made up of cylindrical graphene sheets and can be classified either as single-walled carbon nanotubes (SWCNTs) and multi-walled carbon nanotubes (MWCNTs) [13]. CNTs possess a high specific surface area to mass ratio ranging between 75 and $1020 \mathrm{~m}^{2} / \mathrm{g}$ coupled with an exceptional sorption capacity $[11,188,189]$. They exhibited hydrophobic interactions, van der Waals forces, and $\pi-\pi$ stacking, leading to the formation of four different types of adsorption sites such as inner cavities, interstitial channels, external grooves, and outermost surfaces [190], making them a suitable solid material for photocatalytic degradation of PPCPs. CNTs have interesting properties such as large electron storage capacity, superior metallic conductivity, and light adsorption at a broad range wavelength, thereby making them a suitable solid material in the enhancement of the photocatalytic activity of $\mathrm{TiO}_{2}$ [172]. As monitored on high-performance liquid chromatography, the photocatalytic degradation of oxytetracyclines reaches $88.7 \%$ within 60 min when $\mathrm{MWCNT} / \mathrm{BiVO}_{4}$ composites were utilized. The photocatalytic enhancement was made possible as a result of the synergistic effect that occurs between MWCNTs and $\mathrm{BiVO}_{4}$, which increased the separation rate of photogenerated electron-hole pairs [191].

The usage of $\mathrm{CNTs}-\mathrm{TiO}_{2}$ for the photocatalytic degradation of caffeine was as a result of good contact between CNTs and $\mathrm{TiO}_{2}$, thereby causing a better enhancement in their photocatalytic activity [6]. $\mathrm{CNTs}-\mathrm{TiO}_{2}-\mathrm{N}$ has shown to exhibit a high photocatalytic activity under visible light irradiation for the degradation of ibuprofen [192]. This feature can be attributed to the fact that CNTs can function as electron scavengers resulting in a good binding between $\mathrm{CNTs}, \mathrm{TiO}_{2}$, and $\mathrm{N}$ used. Modification of CNTs on $g-\mathrm{C}_{3} \mathrm{~N}_{4} / \mathrm{BiVO}_{4}$ was evaluated for the degradation of phenol in the presence of solar light irradiation. The synergistic interaction between the heterostructure was aided by $\mathrm{H}_{2} \mathrm{O}_{2}$ as the oxidizing agents for $80.6 \%$ removal of phenol after $2 \mathrm{~h}$, where the $\mathrm{BiVO}_{4}$ helps to promote a better optical absorption ability over the well-contacted structure within the heterojunction while the presence of CNTs in the heterostructure enhances a higher photocatalytic performance as a result of its ability as an electron bridge mediator which is responsible in facilitating the photogenerated charge carrier separation $[193,194]$.

The methods that are employed during its preparation are as follows; hydrothermal, hydrolysis, restrained hydrolysis, simple evaporation and drying, sol-gel, surfactant wrapping sol-gel, chemical vapour deposition, physical vapour deposition, electrophoretic deposition, electrostatic attraction, solvothermal and impregnation [183, 192].

\section{Graphene-based nanocomposites in photocatalysis}

Graphene is made up of a two-dimensional sheet of carbon atoms that are connected by an $\mathrm{sp}^{2}$ bond consisting of an aromatic $\pi$ electron system [195]. Graphene possesses the following properties; high electron mobility, high mechanical strength, high thermal stability, and high specific surface area [196]. These unique properties made graphene have a higher density of potential adsorption sites, which are; open-up surface, a longitudinallyparallel external surface, and interstitial channels [197]. The relevance of graphene includes applications such as in sensors, energy conversion and storage, polymer composite, drug delivery systems, and environmental remediations [198-200]. There are different type of graphene that is available, which are; graphene oxide, reduced graphene oxide, fullerene, carbon nano-onion, and carbon nanotubes [201].

Graphene oxide (GO) and reduced graphene oxide $(\mathrm{rGO})$ are the most commonly used graphene because they show a high efficiency during water treatment. These abilities to adsorb pollutants are due to the presence of several surface functional groups like hydroxyl, carboxyl, and epoxy that function as adsorption sites that aid the removal of contaminants from the water system [202, 203]. Graphene oxide (GO) is prepared via chemical functionalization of graphene through the following method; Brodie [204], Staudenmaier, Hoffman, and Hummer methods [205]. Graphene oxide (GO) is photocatalytically active and can function as an electric insulator as a result of the chemical disruption of the $\pi$ network. Their electrical conductivity can be restored during the conversion of graphene oxide to reduced graphene oxide [206]. Reduced graphene oxide can be prepared using the chemical treatment [207], thermal mediation [208], and electrochemical treatment [209]. Both graphene oxide and reduced graphene oxide can be used for the photocatalytic degradation of PPCPs. GO$\mathrm{TiO}_{2}$ can be prepared via the following method; solution mixing, sol-gel, hydrothermal, electrostatic self-assembly, molecular grafting, chemical exfoliation, liquid phase deposition, and electrospinning [95, 210, 211].

The choice of the method to use will be based on which of them shows a stronger interaction between graphene and the corresponding semiconductor photocatalyst, which in turn will enhance their photocatalytic activity. The degradation of Rhodamine reached $97.2 \%$ when $\mathrm{rGO} / \mathrm{g}-\mathrm{C}_{3} \mathrm{~N}_{4}$ composite was employed. The efficiency of the composites was as a result of the synergistic effect of 
$\mathrm{rGO} / \mathrm{g}-\mathrm{C}_{3} \mathrm{~N}_{4}$ heterostructure formed in the formation of coupled heterointerface and heterojunctions which efficiently and effectively aid in the transfer of photogenerated electron-holes pairs under the influence of visible light where photo-induced electrons can freely migrate along with the conductive network of rGO thereby preventing the recombination of the photogenerated carriers [212]. There is a presence of strong electronic and physical coupling when $\mathrm{TiO}_{2}$ nanosheet-graphene of $2 \mathrm{D}-2 \mathrm{D}$ composite interact, causing an enhancement of electron transfer between them, thus making the photocatalyst superior when used in the removal of 2,4-dichlorophenol as compared to $\mathrm{TiO}_{2}$. This is because of the availability of rich oxygen functional groups on the $2 \mathrm{D}$ surface of rGO, which enhances the ability of rGO to interact with other organic/inorganic compounds to form hybrid composites [213].

Shanavas et al. [213] reported that the advantage in the use of $2 \mathrm{D} / 3 \mathrm{D} / 2 \mathrm{D}$ heterojunction in the photocatalytic degradation of pharmaceuticals such as tetracyclines and ciprofloxacin is the reduction of photoexcited charge carrier migration distance for effective suppression of electron-holes pairs recombination, therefore, creating numerous high-speed photo-induced charge transfer nanochannels in $\mathrm{rGO} / \mathrm{Fe}_{2} \mathrm{O}_{3} / \mathrm{g}-\mathrm{C}_{3} \mathrm{~N}_{4}$ nanocomposite by degrading tetracyclines and ciprofloxacin under visible light irradiation. Also, porous $3 \mathrm{D}$ rGO- $\mathrm{TiO}_{2}$ aerogel has been reported to remove over $99 \%$ of carbamazepine. This was made possible because the macro-porous 3D structure of the aerogel has abundant surface sites, effective charge separation causing an improvement in the mass transportation of the contaminants, thereby leading to easy separation of the catalyst after degrading the contaminants [214].

The excellent outcome experienced during the degradation of carbamazepine, ibuprofen, and sulfamethoxazole, which is up to $80 \%$ during removal and high durability in $45 \mathrm{~h}$ operation, is as a result of the immobilization of $\mathrm{rGO}$ on $\mathrm{TiO}_{2}$ on optical fibers [215]. However, since the photocatalytic activity of solid material immobilized on $\mathrm{TiO}_{2}$ has proved to be efficient in the degradation of PPCPs, there is, therefore, a need to develop a standard method with a pilot-scale experiment to ascertain the cost on a large scale use. Due to the photocatalytic activity of graphene- $\mathrm{TiO}_{2}$ composite, hence their usage in the degradation of PPCPs but their drawback in water treatment arises from the difficulty in separating and recovery of the catalyst after use.

\section{Catalyst preparation methods}

The preparation of different photocatalysts can be achieved through various chemical processes. The synthesis methods are usually tailored to suit the size and morphology of the intended materials. Some simple synthetic techniques that have been used for the synthesis of functional photocatalyst materials are stated below.

\section{Coprecipitation}

The coprecipitation method is a very facile and convenient method used in the synthesis of various photocatalysts. This method involves the dissolution of the salt precursor of interest into an aqueous solution followed by precipitation by addition of a base such as $\mathrm{NaOH}$, $\mathrm{KOH}$. This procedure is usually followed by washing and drying, then calcination of the precipitate at a desirable temperature to obtain the intended products [216]. The particle size, morphology, and composition of the synthesized photocatalyst prepared through this method can be controlled by adjusting different experimental parameters, such as the starting material, their ratio, the surface ligand, the reaction temperature with time, and the $\mathrm{pH}$. Moreover, the size distribution of the as-prepared photocatalyst can be improved by the addition of ligands, such as surfactants, inorganic molecules, and polymers into the reaction medium, however, size control is generally poor for this method [217].

\section{Hydrothermal/solvothermal method}

This method involves the chemical reaction where the precursors are dissolved in a solvent such as water, organic solvents, or $\mathrm{KOH}$. The aqueous mixture will then be subjected to heat at a high temperature around $200{ }^{\circ} \mathrm{C}$ in a sealed stainless steel autoclave. Consequently, the pressure within the reaction autoclave is drastically increased above atmospheric pressure resulting in the generation of high crystalline materials without the need for further treatments [218]. The drawback of this method is its low yield of products when compared with the coprecipitation method.

\section{Thermal decomposition method}

Thermal decomposition is an innovative method to synthesize stable nanoparticles. This method involves the thermolysis of organometallic complex precursors in high-boiling-point organic solvents in the presence of surfactants to synthesize nanoparticles of various materials. It is faster, clearer, and economical when compared with other methods [219]. It is also one of the easiest and the most convenient method used to synthesize monodispersed metal nanoparticles. Furthermore, it answers the greatest challenge of obtaining a controlled nanometric size and shape in nanotechnology research, which is achieved by controlling the concentrations of the precursors and surfactants; the solvent; and the experimental parameters such as heating rate, heating temperature, and heating time are usually regulated [217]. However, 
photocatalyst prepared by this method is usually coated with hydrophobic ligands, thereby making it insoluble in water. Therefore, a further surface modification step is required to render these nanoparticles water-soluble for efficient photocatalytic applications.

\section{Sol-gel method}

The sol-gel method for the synthesis of nanomaterials is a convenient and versatile reaction technique in the synthesis of numerous functional photocatalyst. The sol-gel process is based on hydrolysis and polycondensation reaction involving the addition of a complexing agent such as; a polymer, citric acid, or other suitable organic entities into a solution of a colloidal dispersion of the metal ions of the target material. These complexing agents function as cross-linkers between the ionic substances in solution followed by gradual removal of the solvent molecules from the mixture to form a thick gel. The gel is then dried and pre-calcined to obtain the as-prepared powder. The as-prepared powders are then annealed at higher temperatures to obtain the finished product. Metal oxides can also be used as starting materials in this method [220, 221].

Several parameters, such as type of precursor, type of solvent, water content, $\mathrm{pH}$, the concentration of precursor and temperature, can influence the structure of the initial gel, which in turn influenced the properties of the resulting materials, including the crystal structure, particle size, shape and crystallinity [222, 223]. The solgel method possesses many advantages. For instance, it allows tailoring of both the bulk properties, including phase composition and surface characteristics such as the surface area, the total pore volume distribution, etc., of a material on a nanometer scale from the earliest stages of processing. The main drawbacks are in the possible high cost for the majority of alkoxide precursors, and processing steps are long.

\section{The use of graphitic carbon nitride $\left(g-C_{3} N_{4}\right)$ as an efficient catalyst for the degradation of pharmaceuticals}

The large band gap energy of semiconductor photocatalysts such as $\mathrm{TiO}_{2}(3.2 \mathrm{eV}), \mathrm{ZnO}_{2}(3.37 \mathrm{eV})$, constitute a significant limitation to their photocatalytic usage under visible light spectrum due to its low utilization of solar energy. This limitation makes this method an expensive means for the photocatalytic process; hence the urgent need to research more on visible light semiconductor photocatalyst. g- $\mathrm{C}_{3} \mathrm{~N}_{4}$ has emerged one of the next generation photocatalysts due to its cheap synthesis, fascinating electronic band structure, non-toxic, graphene-like two-dimensional structure coupled with good visible light adsorption ability and chemical stability for removal of hazardous pollutants from the environment and clean energy production [224, 225]. They are made up of two main units to establish their allotropic nature which are; tri-s-trianzine/heptazine $\left(\mathrm{C}_{6} \mathrm{~N}_{7}\right)$ and s-triazine $\left(\mathrm{C}_{3} \mathrm{~N}_{3}\right)$ rings (Fig. 3); where the tri-s-triazine based g- $\mathrm{C}_{3} \mathrm{~N}_{4}$ is highly favoured and the most stable phase of g- $\mathrm{C}_{3} \mathrm{~N}_{4}$ thermodynamically [226].

Since the discovery of $\mathrm{g}-\mathrm{C}_{3} \mathrm{~N}_{4}$ by Wang et al. [225] as a promising visible light photocatalyst for the evolution of $\mathrm{H}_{2}$, much effort has been directed towards its synthesis. g- $\mathrm{C}_{3} \mathrm{~N}_{4}$ can be prepared by thermal polymerization using the following precursors based on different reaction conditions and differences in the material degrees of condensation; cyanamide, dicyandiamide, melamine, urea, thiourea and ammonium thiocyanate [227-229]. g- $\mathrm{C}_{3} \mathrm{~N}_{4}$ has a low energy band gap between 2.7 and $2.8 \mathrm{eV}$ as a result of the presence of $\mathrm{sp}^{2}$-hybridized carbon and nitrogen forming the $\pi$-conjugated electronic structure, possess excellent chemical stability, does not dissolve in acid, alkali or organic solvents making it to be environmentally friendly material $[229,230]$.

However, their application in environmental remediations are limited by several obstacles such as low specific surface area, the high recombination rate of charge carrier and low electrical conductivity, hence the need to develop a modified g- $\mathrm{C}_{3} \mathrm{~N}_{4}$-based heterojunction photocatalyst with improved physicochemical properties that can be applied in the degradation of organic pollutants in the environment $[231,232]$. The modification can be achieved through exfoliation of bulk g- $\mathrm{C}_{3} \mathrm{~N}_{4}$ into nanosheet, nanotubes and quantum dots, deposition of noble metal, doping with metal, coupling with other semiconductors such as $\mathrm{TiO}_{2}, \mathrm{ZnO}, \mathrm{Ag}_{2} \mathrm{O}, \mathrm{MoS}_{2}$, incorporating with carbonaceous materials like; activated carbon, graphene oxides, reduced graphene oxide, carbon nanotubes, and many others to form nanocomposites [233-235].

\section{Modification of $\mathrm{g}-\mathrm{C}_{3} \mathrm{~N}_{4}$}

To overcome the drawback in $\mathrm{g}-\mathrm{C}_{3} \mathrm{~N}_{4}$ associated with their photocatalytic application, specific surface area, charge separation, and opticals for $g-\mathrm{C}_{3} \mathrm{~N}_{4}$ have been improved. Numerous heterostructure based g- $\mathrm{C}_{3} \mathrm{~N}_{4}$ photocatalyst has been prepared by many researchers with improved suitable band structures, shaped at the interfaces between $\mathrm{g}-\mathrm{C}_{3} \mathrm{~N}_{4}$ and metal particles, inorganic semiconductors or carbonaceous materials have shown to enhance their charge carrier separation leading to its improvement in their photodegradation activity [236-238]. Hence, the interest in the synthesis of heterostructure based $g-\mathrm{C}_{3} \mathrm{~N}_{4}$ with suitable band position resulting in the suppression of the recombination rate of the photogenerated electron-hole pairs for improved 


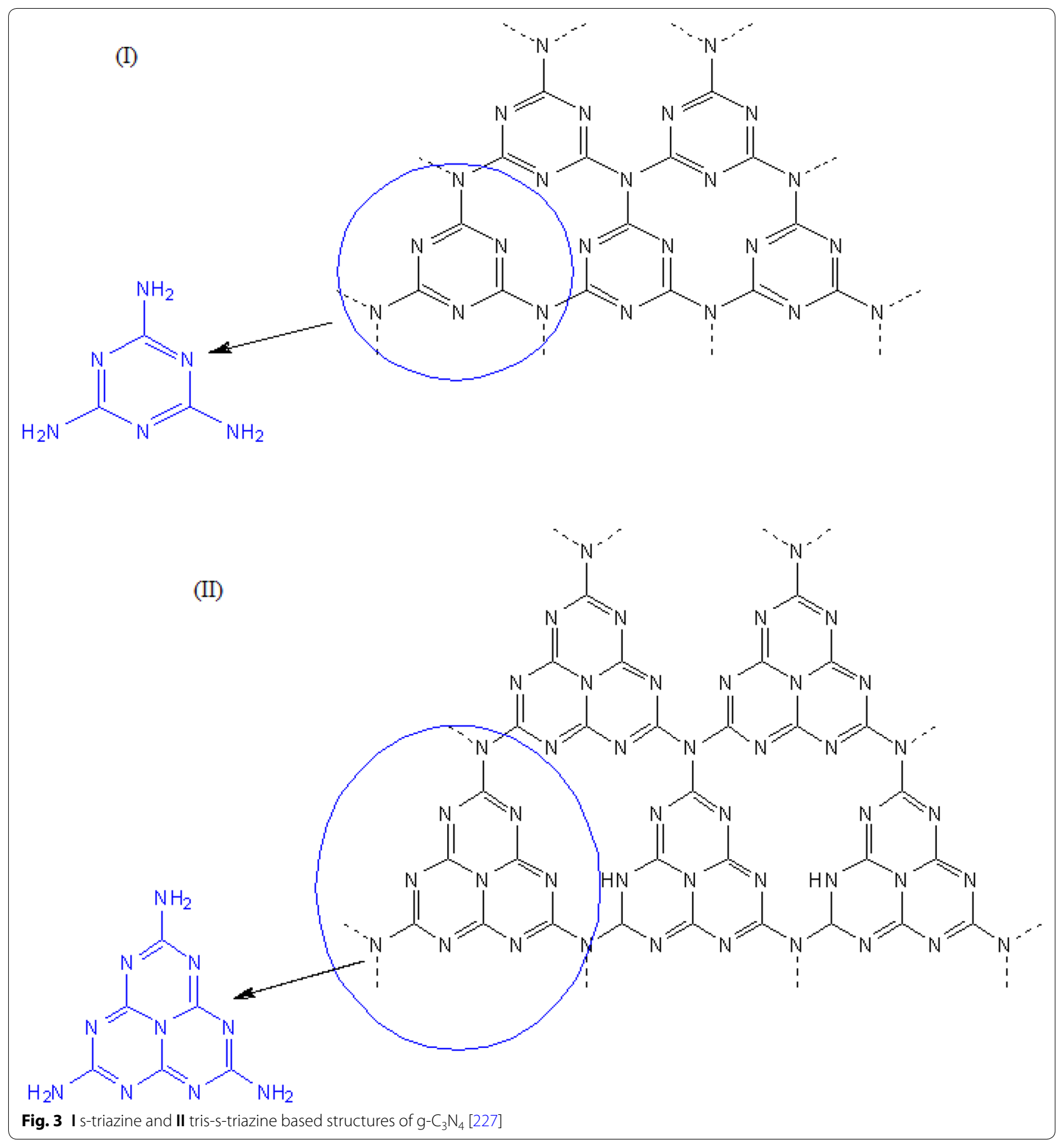

photocatalytic degradation of hazardous contaminants from the environments.

Fabrication of g- $\mathrm{C}_{3} \mathrm{~N}_{4}$ based semiconductor photocatalyst is considered as one of the effective and more feasible strategies to enhance the photocatalytic activity of $\mathrm{g}-\mathrm{C}_{3} \mathrm{~N}_{4}$ where the formation of a heterojunction system improve the photo-generated electron-hole pairs separation leading to the improvement in their photocatalytic activity as seen in the following $\mathrm{g}_{-} \mathrm{C}_{3} \mathrm{~N}_{4}$ based photocatalyst g- $\mathrm{C}_{3} \mathrm{~N}_{4} / \mathrm{TiO}_{2}, \mathrm{~g}-\mathrm{C}_{3} \mathrm{~N}_{4} / \mathrm{WO}_{3}, \mathrm{~g}-\mathrm{C}_{3} \mathrm{~N}_{4} / \mathrm{CdS}$, g- $\mathrm{C}_{3} \mathrm{~N}_{4} / \mathrm{Cu}_{2} \mathrm{O}, \mathrm{g}-\mathrm{C}_{3} \mathrm{~N}_{4} / \mathrm{CdS} / \mathrm{Cu}_{2} \mathrm{O}$ for the degradation of numerous organic pollutants in the environment [239-241]. 
Chen et al. [242] synthesized a series of visiblelight-driven $\mathrm{MgIn}_{2} \mathrm{~S}_{4} / g-\mathrm{C}_{3} \mathrm{~N}_{4}$ heterostructures for the degradation of 4-nitroaniline and methyl orange. The improvement in the photocatalytic activity of $\mathrm{MgIn}_{2} \mathrm{~S}_{4} / \mathrm{g}-\mathrm{C}_{3} \mathrm{~N}_{4}$ can be attributed to the faster charge separation and transport that existed between the interfaces and band structures of $\operatorname{MgIn}_{2} \mathrm{~S}_{4}$ nanoplates and $\mathrm{g}-\mathrm{C}_{3} \mathrm{~N}_{4}$ nanosheets making it an efficient visiblelight-driven composite for the degradation of hazardous pollutants. The photocatalytic performance of $\mathrm{Z}$-scheme g- $\mathrm{C}_{3} \mathrm{~N}_{4} / \mathrm{CdS}$ composites for the degradation of erythromycin and tetracycline was remarkably enhanced as compared to that of pure g- $\mathrm{C}_{3} \mathrm{~N}_{4}$ and $\mathrm{CdS}$ owing to the perfect matching of the band gap, the interface of the close photocatalyst was lower than that of CdS which give rise to the formation of heterojunction with $\mathrm{g}-\mathrm{C}_{3} \mathrm{~N}_{4}$ which suppresses the photo corrosion of CdS [243].

Table 2 below shows how different heterostructure composites have been used for the degradation of various organic pollutants.

\section{Mechanism of g- $\mathrm{C}_{3} \mathrm{~N}_{4}$ photocatalyst}

The absorption of photon energy by $g-\mathrm{C}_{3} \mathrm{~N}_{4}$ photocatalyst, which is either equal or greater than the band energy of $\mathrm{g}-\mathrm{C}_{3} \mathrm{~N}_{4}$ leads to the generation of electrons $\left(\mathrm{e}^{-}\right)$in the valence band $(\mathrm{VB})$ to be excited before migrating to the conduction band $(\mathrm{CB})$. The generated electron will be excited and leave the photo-generated holes $\left(\mathrm{h}^{+}\right)$in the valence band. Both the photoexcited electron $\left(\mathrm{e}^{-}\right)$and photogenerated holes $\left(\mathrm{h}^{+}\right)$will be trapped at the surface of the catalyst where the $\mathrm{h}^{+}$react with absorbed $\mathrm{H}_{2} \mathrm{O}$ to produce .OH radicals while $\mathrm{e}^{-}$react with absorbed $\mathrm{O}_{2}$ to produce . $\mathrm{O}_{2}^{-}$radicals before reacting with organic pollutants and finally degrade them $[254,255]$. The mechanism is summarized below;

$$
\begin{aligned}
& \mathrm{g}-\mathrm{C}_{3} \mathrm{~N}_{4} \stackrel{\mathrm{hv}}{\longrightarrow} \mathrm{e}^{-}{ }_{\mathrm{CB}}\left(\mathrm{g}-\mathrm{C}_{3} \mathrm{~N}_{4}\right)+\mathrm{h}^{+}{ }_{\mathrm{vB}}\left(\mathrm{g}-\mathrm{C}_{3} \mathrm{~N}_{4}\right) \\
& \mathrm{e}_{\mathrm{CB}}^{-}\left(\mathrm{g}-\mathrm{C}_{3} \mathrm{~N}_{4}\right)+\mathrm{O}_{2} \rightarrow \mathrm{O}_{2}^{-} \\
& \mathrm{h}_{\mathrm{VB}}^{+}\left(\mathrm{g}-\mathrm{C}_{3} \mathrm{H}_{4}\right)+\mathrm{OH}^{-} \rightarrow \cdot \mathrm{OH}
\end{aligned}
$$

\begin{tabular}{|c|c|c|c|c|c|c|}
\hline Photocatalyst & Synthesis method & Pollutants & $\begin{array}{l}\text { Removal } \\
\text { efficiency } \\
(\%)\end{array}$ & Time & Light source & References \\
\hline \multirow[t]{4}{*}{$g-C_{3} N_{4}$} & \multirow[t]{4}{*}{ Polycondensation } & Ibuprofen & 20 & \multirow[t]{4}{*}{$4 \mathrm{~h}$} & \multirow[t]{4}{*}{35 W Xenon lamp } & \multirow[t]{4}{*}[244]{} \\
\hline & & Aspirin & 30 & & & \\
\hline & & Ciprofloxaci n & 60 & & & \\
\hline & & Tetracycline & 86 & & & \\
\hline $\mathrm{BaTiO}_{3} / \mathrm{TiO}_{2}$ & One-step calcination & Acetaminophen & 95 & $4 \mathrm{~h}$ & 500 W Xenon lamp & {$[245]$} \\
\hline \multirow[t]{2}{*}{$\mathrm{ZnO} / \mathrm{g}-\mathrm{C}_{3} \mathrm{~N}_{4}$} & \multirow[t]{2}{*}{ Thermal condensation } & Tetracycline & 78.4 & \multirow[t]{2}{*}{$50 \mathrm{~min}$} & \multirow[t]{2}{*}{300 W Xenon lamp } & \multirow[t]{2}{*}[246]{} \\
\hline & & Oxytetracycline & 63.5 & & & \\
\hline $\mathrm{Ag} / \mathrm{g}-\mathrm{C}_{3} \mathrm{~N}_{4}$ & Photo-reduction & Sulfamethazole & 99.5 & $60 \mathrm{~min}$ & 300 W Xenon lamp & {$[247]$} \\
\hline $\mathrm{g}-\mathrm{C}_{3} \mathrm{~N}_{4} / \mathrm{TiO}_{2} / \mathrm{Fe}_{3} \mathrm{O}_{4} @ \mathrm{SiO}_{2}$ & Sol-gel & Ibuprofen & 92 & $3 \mathrm{~h}$ & $330 \mathrm{Wm}^{-2}$ compart fluorescent lamps & {$[248]$} \\
\hline \multirow[t]{2}{*}{$\mathrm{g}-\mathrm{C}_{3} \mathrm{~N}_{4} / \mathrm{MoS}_{2}$} & \multirow[t]{2}{*}{ Hydrothermal } & Levofloxaci n & 75.81 & $140 \min$ & \multirow[t]{2}{*}{ Ultrasonic wave at $30 \mathrm{kHz}$} & \multirow[t]{2}{*}[234]{} \\
\hline & & Methylene Blue & 98.43 & $14 \min$ & & \\
\hline $\mathrm{Ag}_{3} \mathrm{PO}_{4} / \mathrm{GO} / \mathrm{g}-\mathrm{C}_{3} \mathrm{~N}_{4}$ & Chemical precipitation & Rhodamine B & 94.8 & $50 \min$ & 150 W Xenon lamp & {$[249]$} \\
\hline \multirow[t]{4}{*}{ BiVO4/TiO2/RGO } & \multirow[t]{4}{*}{ Hydrothermal } & Tetracycline & 96.2 & \multirow[t]{4}{*}{$60 \min$} & \multirow[t]{4}{*}{1000 W Xenon lamp } & \multirow[t]{4}{*}[250]{} \\
\hline & & Oxytetracycline & 97.5 & & & \\
\hline & & Chlortetracycline & 98.7 & & & \\
\hline & & Doxycycline & 99.6 & & & \\
\hline $\mathrm{Ag}_{2} \mathrm{O} / \mathrm{CeO}_{2}$ & Thermal deposition & Enrofloxacin & 87.11 & 120 & 300 W Xenon lamp & {$[251]$} \\
\hline $\mathrm{g}-\mathrm{C}_{3} \mathrm{~N}_{4} / \mathrm{CNT} / \mathrm{BiVO}_{4}$ & Wet impregnation & Phenol & 80.6 & $120 \min$ & $\begin{array}{l}\text { Sunlight (illumination intensity; } 500 \text { W } \\
\text { halogen lamp) }\end{array}$ & {$[192]$} \\
\hline \multirow[t]{2}{*}{$\mathrm{g}-\mathrm{C}_{3} \mathrm{~N}_{4} / \mathrm{AgBr} / \mathrm{rGO}$} & \multirow[t]{2}{*}{ Hydrothermal reaction } & Tetracycline & 78.4 & $90 \min$ & \multirow[t]{2}{*}{250 W Xenon lamp } & \multirow[t]{2}{*}[252]{} \\
\hline & & 2,4-Dichlorophenol & 68.2 & $6 \mathrm{~h}$ & & \\
\hline \multirow[t]{2}{*}{$\mathrm{rGO} / \mathrm{WS}_{2} / \mathrm{Mg}$-doped $\mathrm{ZnO}$} & \multirow{2}{*}{$\begin{array}{l}\text { Electrostatic self- } \\
\text { assembly and copre- } \\
\text { cipitation }\end{array}$} & \multirow[t]{2}{*}{ Rhodamine B } & 95 & $14 \min$ & UV lamp & \multirow[t]{2}{*}[253]{} \\
\hline & & & 90 & $90 \mathrm{~min}$ & Solar light & \\
\hline
\end{tabular}

Table 2 Different synthesized heterostructure composites for the degradation of various organic pollutants 


$$
\begin{aligned}
& \mathrm{O}_{2}^{-}+\text {Organic pollutants } \rightarrow \mathrm{CO}_{2}+\mathrm{H}_{2} \mathrm{O} \\
& \cdot \mathrm{OH}+\text { Organic pollutants } \rightarrow \mathrm{CO}_{2}+\mathrm{H}_{2} \mathrm{O} .
\end{aligned}
$$

However, in the photocatalytic process for the degradation of organic pollutants, it is crucial to understand the transformation of the different intermediates involved in photocatalysis as it will provide information about the toxicity of the intermediates as well as risk assessment. A schematic representation of photocatalysis mechanism is shown in Fig. 4.

Although many works have been done in fabricating a g- $\mathrm{C}_{3} \mathrm{~N}_{4}$ based photocatalyst for environmental remediation, however, much effort needs to be directed towards the construction of g- $\mathrm{C}_{3} \mathrm{~N}_{4}$-based heterostructure photocatalyst. This act would improve the separation of photogenerated electrons and inhibit the electron-hole pair recombination with an excellent possibility for an efficient and effective photocatalytic activity for the degradation of pharmaceuticals under visible light irradiation.

\section{Conclusion}

In conclusion, this review highlighted a detailed overview of the detection of organic pollutants such as pharmaceuticals and personal care products, endocrine-disrupting chemicals, organic dyes, and various industrials waste in environmental matrices. Additionally, it was revealed that most researches focus on the occurrence of the parent pharmaceutical compound while the transformation products which may even be more toxic than the parent drugs are ignored, hence more focus is needed on how the chronic exposure to these contaminants affect humans and other ecosystems, particularly the nontarget organisms. The environmental impacts of these emerging contaminants led to the need for the development of a technology for its removal from the environment. This problem of pharmaceutical contamination of the environment could be attributed to the inability of the wastewater treatment plants to completely remove the contaminants, making them one of the common sources through which these pharmaceuticals get into the environment. Even though various methods such as activated sludge, wetlands, adsorption, membrane processes have been developed for the removal of these pollutants, unfortunately, many research reports have proven that these methods are ineffective in removing these contaminants. Hence, the advanced oxidation process using a photocatalytic method becomes relevant. In this method, various semiconducting photocatalyst can be immobilized on carbonaceous materials, metal oxides, or another semiconductor as the best alternative for the degradation and mineralization of these organic pollutants into harmless products and at the same time, the catalyst can still be recovered and recycled.

Moreover, it should be noted that from the various reports reviewed, photocatalyst materials emerged as an efficient and effective technology for the degradation of various organic pollutants ranging from pharmaceutical and personal care products to different dyes. Furthermore, the engineering of metal-free carbon-based photocatalyst holds a great advantage as an efficient and effective means in degrading organic pollutants because of their tunable band gap, visible light responses, the formation of complex structures, excellent chemical stability, economical, reusability, and ease of fabrication. However, despite the significant progress made in the synthesis of photocatalyst for environmental remediation, their photocatalytic performance for degradation and mineralization of pharmaceutical and personal care products with their intermediates still need additional improvement for practical application. Also, their activities are limited by insufficient light absorption, rapid electron-hole pair's recombination rate, difficulty in the separation and recycle of photocatalysts, and photo-corrosion of some semiconductor photocatalysts. The process might be complicated at times, costly, and time-consuming, hence the need to develop a method that is more efficient, easy, affordable, and environmentally friendly for the removal of organic pollutants at the WWTPs. Thus, the need for the green synthetic routes for more novel based heterostructure photocatalyst. In

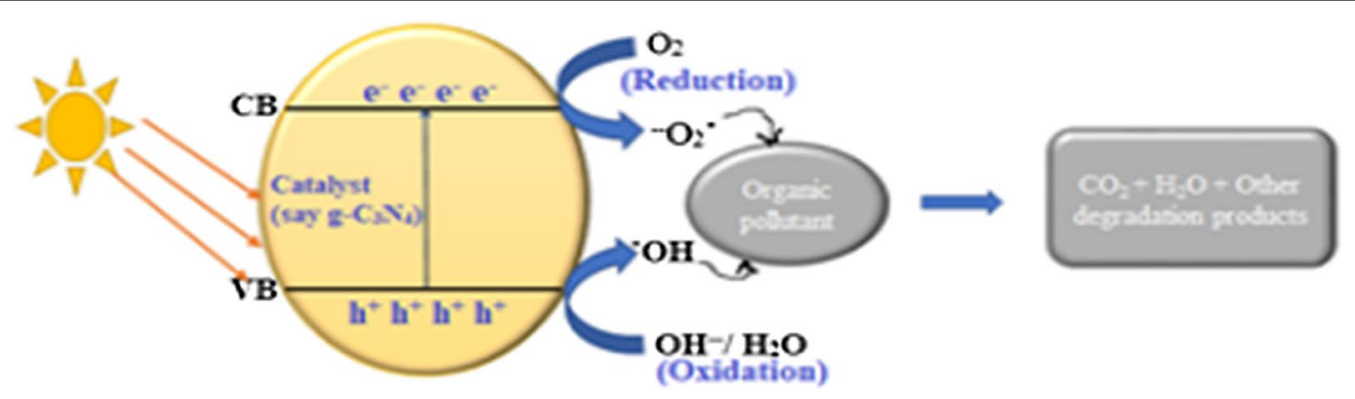

Fig. 4 Schematic representation of photocatalysis mechanism (adapted with modification from [256]) 
addition, the synergistic effects that existed within the heterostructure photocatalyst, which aid their photocatalytic activity, need more investigation. The mechanism of the degradation pathways, also, needs much attention to be able to verify the most active reactive species in photodegradation of organic pollutants. Finally, this review tends to serve as a great advantage for material scientists and nanotechnologists who are interested in seeking materials for environmental degradation of organic pollutants.

\begin{abstract}
Abbreviations
AC: Activated carbon; AOPs: Advanced oxidation processes; CB: Conduction band; CNTs: Carbon nanotubes; COD: Chemical oxygen demand; DCF: Diclofenac; EPA: Environmental Prevention Agency; eV: Band gap energy; GCMS: Gas chromatography mass spectrometry; GO: Graphene oxide; LCMS: Liquid chromatography mass spectrometry; LOD: Below limit of detection; LOQ: Below limit of quantification; NSAIDs: Non-steroidal anti-inflammatory drugs; PPCPs: Pharmaceuticals and personal care products; RGO: Reduced graphene oxide; UHPLC: Ultra-high-performance liquid chromatography; UV: Ultraviolet light; VB: Valence bond; WWTPs: Wastewater treatment plant.
\end{abstract}

\section{Acknowledgements}

Not applicable.

\section{Authors' contributions}

AO conducted desk study and collected and analyzed relevant review information/data, and prepared the first draft of the paper in conjunction with EOO and OSO. EOO analyzed review information/data and revised the initial draft of the paper. OO conceived the idea, contributed, wrote some sections, read and edited the manuscript. All authors read and approved the final manuscript.

\section{Funding}

No funding was received for this work.

\section{Availability of data and materials}

All the information and data cited in this review were generated from literature research and listed in the references. The information, datasets used and analyzed during the current study are available from the corresponding author on reasonable request. We have presented all data in the form of tables and figures.

\section{Ethics approval and consent to participate}

Not applicable.

\section{Consent for publication}

Not applicable.

\section{Competing interests}

The authors declare that they have no competing interests.

Received: 17 September 2019 Accepted: 8 October 2020

Published online: 22 October 2020

\section{References}

1. Ternes T, Adriano J, Jörg O (2015) Occurrence, fate, removal and assessment of emerging contaminants in water in the water cycle (from wastewater to drinking water). Water Res 72:1-2

2. Vandermeersch G, Lourenço HM, Alvarez-Muñoz D et al (2015) Environmental contaminants of emerging concern in seafood-European database on contaminant levels. Environ Res 143:29-45
3. Alves RN, Maulvault AL, Barbosa VL et al (2017) Preliminary assessment on the bioaccessibility of contaminants of emerging concern in raw and cooked seafood. Food Chem Toxicol 104:69-78

4. Valdés ME, Amé MV, de los Angeles Bistoni M et al (2014) Occurrence and bioaccumulation of pharmaceuticals in a fish species inhabiting the Suquía River basin (Córdoba, Argentina). Sci Total Environ 472:389-396

5. Bolong N, Ismail A, Salim MR et al (2009) A review of the effects of emerging contaminants in wastewater and options for their removal. Desalination 239(1-3):229-246

6. Yuan C, Hung C-H, Li H-W et al (2016) Photodegradation of ibuprofen by $\mathrm{TiO}_{2}$ co-doping with urea and functionalized CNT irradiated with visible light-effect of doping content and $\mathrm{pH}$. Chemosphere 155:471-478

7. Adeleye AS, Conway JR, Garner K et al (2016) Engineered nanomaterials for water treatment and remediation: costs, benefits, and applicability. Chem Eng 286:640-662

8. Ramgopal G, Vidya Y, Anantharaju K et al (2015) Bio-inspired synthesis of $\mathrm{Y}_{2} \mathrm{O}_{3}$ : $\mathrm{Eu}^{3+}$ red nanophosphor for eco-friendly photocatalysis. Spectrochimica Acta A 141:149-160

9. Tyagi I, Gupta V, Sadegh H et al (2017) Nanoparticles as adsorbent; a positive approach for removal of noxious metal ions: a review. Sci Technol Dev 34(3):195-214

10. Prakash K, Kumar JV, Latha P et al (2019) Fruitful fabrication of CDs on $\mathrm{GO} / \mathrm{g}-\mathrm{C}_{3} \mathrm{~N}_{4}$ sheets layers: a carbon amalgamation for the remediation of carcinogenic pollutants. J Photochem Photobiol A Chem 370:94-104

11. Jung C, Son A, Her N et al (2015) Removal of endocrine disrupting compounds, pharmaceuticals, and personal care products in water using carbon nanotubes: a review. J Ind Eng Chem 27:1-11

12. Anjali R, Shanthakumar S (2019) Insights on the current status of occurrence and removal of antibiotics in wastewater by advanced oxidation processes. J Environ Manag 246:51-62

13. Czech B, Buda W (2016) Multicomponent nanocomposites for elimination of diclofenac in water based on an amorphous $\mathrm{TiO}_{2}$ active in various light sources. J Photochem Photobiol A Chem 330:64-70

14. Hou Y, Yuan $G$, Wang $S$ et al (2020) Nitrofurazone degradation in the self-biased bio-photoelectrochemical system: $\mathrm{g}-\mathrm{C}_{3} \mathrm{~N}_{4} / \mathrm{CdS}$ photocathode characterization, degradation performance, mechanism and pathways. J Hazard Mater 384:121438

15. Shao B, Liu X, Liu Z et al (2019) Synthesis and characterization of 2D/OD $\mathrm{g}-\mathrm{C}_{3} \mathrm{~N}_{4} / \mathrm{CdS}$-nitrogen doped hollow carbon spheres (NHCs) composites with enhanced visible light photodegradation activity for antibiotic. Chem Eng 374:479-493

16. Ebele AJ, Abdallah MA-E, Harrad S (2017) Pharmaceuticals and personal care products (PPCPS) in the freshwater aquatic environment. Emerg Contam 3(1):1-16

17. Veach A, Bernot MJ, Mitchell JK (2012) The influence of six pharmaceuticals on freshwater sediment microbial growth incubated at different temperatures and UV exposures. Biodegradation 23(4):497-507

18. Klosterhaus SL, Grace R, Hamilton MC et al (2013) Method validation and reconnaissance of pharmaceuticals, personal care products, and alkylphenols in surface waters, sediments, and mussels in an urban estuary. Environ Int 54:92-99

19. Ternes TA, Joss A, Siegrist H (2004) Peer reviewed: scrutinizing pharmaceuticals and personal care products in wastewater treatment. ACS Publications, Washington, DC

20. Blair B, Nikolaus A, Hedman C et al (2015) Evaluating the degradation, sorption, and negative mass balances of pharmaceuticals and personal care products during wastewater treatment. Chemosphere 134:395-401

21. Petrie B, Barden R, Kasprzyk-Hordern B (2015) A review on emerging contaminants in wastewaters and the environment: current knowledge, understudied areas and recommendations for future monitoring. Water Res 72:3-27

22. Agunbiade FO, Moodley B (2014) Pharmaceuticals as emerging organic contaminants in Umgeni River water system, KwaZulu-Natal, South Africa. Environ Monit Assess 186(11):7273-7291

23. Amdany R, Chimuka L, Cukrowska E (2014) Determination of naproxen, ibuprofen and triclosan in wastewater using the polar organic chemical integrative sampler (POCIS): a laboratory calibration and field application. Water SA 40(3):407-414 
24. Matongo S, Birungi G, Moodley B et al (2015) Pharmaceutical residues in water and sediment of Msunduzi River, kwazulu-natal, South Africa. Chemosphere 134:133-140

25. Li J-D, Cai Y-Q, Shi Y-L et al (2007) Determination of sulfonamide compounds in sewage and river by mixed hemimicelles solid-phase extraction prior to liquid chromatography-spectrophotometry. J Chromatogr A 1139:178-184

26. Watkinson A, Murby E, Kolpin DW, Costanzo S (2009) The occurrence of antibiotics in an urban watershed: from wastewater to drinking water. Sci Total Environ 407:2711-2723

27. Zhou J, Zhang Z, Banks E et al (2009) Pharmaceutical residues in wastewater treatment works effluents and their impact on receiving river water. J Hazard Mater 166:655-661

28. Agunbiade FO, Moodley B (2016) Occurrence and distribution pattern of acidic pharmaceuticals in surface water, wastewater, and sediment of the Msunduzi River, Kwazulu-Natal, South Africa. Environ Toxicol 35:36-46

29. Kasprzyk-Hordern B, Dinsdale RM, Guwy AJ (2008) The occurrence of pharmaceuticals, personal care products, endocrine disruptors and illicit drugs in surface water in South Wales, UK. Water Res 42:3498-3518

30. Gros M, Petrovic M, Barceló D (2009) Tracing pharmaceutical residues of different therapeutic classes in environmental waters by using liquid chromatography/quadrupole-linear ion trap mass spectrometry and automated library searching. Anal Chem 81:898-912

31. Metcalfe CD, Koenig BG, Bennie DT et al (2003) Occurrence of neutral and acidic drugs in the effluents of Canadian sewage treatment plants. Environ Toxicol Chem 22:2872-2880

32. Kim J, Yoon S, Lee S et al (2012) Occurrence and fate of PPCPs wastewater treatment plants in Korea. In: 2nd international conference on environment and industrial innovation, Singapore, pp 57-61

33. Brun GL, Bernier M, Losier R et al (2006) Pharmaceutically active compounds in Atlantic Canadian sewage treatment plant effluents and receiving waters, and potential for environmental effects as measured by acute and chronic aquatic toxicity. Environ Toxicol Chem 25:2163-2176

34. Rabiet M, Togola A, Brissaud F et al (2006) Consequences of treated water recycling as regards pharmaceuticals and drugs in surface and ground waters of a medium-sized Mediterranean catchment. Environ Sci Technol 40:5282-5288

35. Lin W-C, Chen H-C, Ding W-H (2005) Determination of pharmaceutical residues in waters by solid-phase extraction and large-volume on-line derivatization with gas chromatography-mass spectrometry. J Chromatogr A 1065:279-285

36. Kimura K, Hara H, Watanabe Y (2007) Elimination of selected acidic pharmaceuticals from municipal wastewater by an activated sludge system and membrane bioreactors. Environ Sci Technol 41:3708-3714

37. Wang Y, Wang X, Li M et al (2018) Removal of pharmaceutical and personal care products (PPCPs) from municipal waste water with integrated membrane systems, MBR-RO/NF. Int J Environ Res Public Health $15: 269$

38. Zhang Z, Feng Y, Gao P et al (2011) Occurrence and removal efficiencies of eight EDCs and estrogenicity in a STP. J Environ Monit 13:1366-1373

39. Van Zijl MC, Aneck-Hahn NH, Swart P et al (2017) Estrogenic activity, chemical levels and health risk assessment of municipal distribution point water from Pretoria and Cape Town, South Africa. Chemosphere 186:305-313

40. Kuch HM, Ballschmiter K (2001) Determination of endocrine-disrupting phenolic compounds and estrogens in surface and drinking water by HRGC-(NCl)-MS in the picogram per liter range. Environ Sci Technol 35:3201-3206

41. Archana G, Dhodapkar R, Kumar A (2016) Offline solid-phase extraction for preconcentration of pharmaceuticals and personal care products in environmental water and their simultaneous determination using the reversed phase high-performance liquid chromatography method. Environ Monit Assess 188:512

42. Manickum T, John W (2014) Occurrence, fate and environmental risk assessment of endocrine disrupting compounds at the wastewater treatment works in Pietermaritzburg (South Africa). Sci Total Environ 468:584-597

43. Huang $\mathrm{CH}$, Sedlak DL (2001) Analysis of estrogenic hormones in municipal wastewater effluent and surface water using enzyme-linked immunosorbent assay and gas chromatography/tandem mass spectrometry. Environ Toxicol Chem 20:133-139

44. Daughton CG, Ternes TA (1999) Pharmaceuticals and personal care products in the environment: agents of subtle change? Environ Health Perspect 107(suppl 6):907-938

45. Yang Y, Ok YS, Kim K-H et al (2017) Occurrences and removal of pharmaceuticals and personal care products (PPCPs) in drinking water and water/sewage treatment plants: a review. Sci Total Environ 596:303-320

46. Tseng W-JS-W, Tsai (2019) Assessment of dermal exposures for synthetic musks from personal care products in Taiwan. Sci Total Environ 669:160-167

47. Juliano C, Magrini GA (2017) Cosmetic ingredients as emerging pollutants of environmental and health concern. A mini-review. Cosmetics $4(2): 11$

48. Dann AB, Hontela A (2011) Triclosan: environmental exposure, toxicity and mechanisms of action. J Applied Toxicol 31(4):285-311

49. Tijani JO, Fatoba OO, Babajide OO et al (2016) Pharmaceuticals, endocrine disruptors, personal care products, nanomaterials and perfluorinated pollutants: a review. Environ Chem Lett 14(1):27-49

50. Langford KH, Thomas KV (2009) Determination of pharmaceutical compounds in hospital effluents and their contribution to wastewater treatment works. Environ Int 35(5):766-770

51. Fick J, Söderström H, Lindberg RH et al (2009) Contamination of surface, ground, and drinking water from pharmaceutical production. Environ Toxicol Chem 28(12):2522-2527

52. Boxall AB, Rudd MA, Brooks BW et al (2012) Pharmaceuticals and personal care products in the environment: what are the big questions? Environ Health Perspect 120(9):1221-1229

53. Maletz S, Floehr T, Beier S et al (2013) In vitro characterization of the effectiveness of enhanced sewage treatment processes to eliminate endocrine activity of hospital effluents. Water Res 47(4):1545-1557

54. Al Aukidy M, Verlicchi P, Voulvoulis N (2014) A framework for the assessment of the environmental risk posed by pharmaceuticals originating from hospital effluents. Sci Total Environ 493:54-64

55. Brausch JM, Connors KA, Brooks BW et al (2012) Human pharmaceuticals in the aquatic environment: a review of recent toxicological studies and considerations for toxicity testing. In: Reviews of environmental contamination and toxicology, vol 218. Springer, Boston, pp 1-99

56. Sui Q, Cao X, Lu S et al (2015) Occurrence, sources and fate of pharmaceuticals and personal care products in the groundwater: a review. Emerg Contam 1(1):14-24

57. Del Rosario KL, Mitra S, Humphrey CP Jr et al (2014) Detection of pharmaceuticals and other personal care products in groundwater beneath and adjacent to onsite wastewater treatment systems in a coastal plain shallow aquifer. Sci Total Environ 487:216-223

58. Wang J, Wang S (2016) Removal of pharmaceuticals and personal care products (PPCPs) from wastewater: a review. J Environ Manag 182:620-640

59. Weigel $S$, Berger $U$, Jensen E et al (2004) Determination of selected pharmaceuticals and caffeine in sewage and seawater from Tromsø/ Norway with emphasis on ibuprofen and its metabolites. Chemosphere 56(6):583-592

60. Awfa D, Ateia M, Fujii M et al (2018) Photodegradation of pharmaceuticals and personal care products in water treatment using carbonaceous- $\mathrm{TiO}_{2}$ composites: a critical review of recent literature. Water Res 142:26-45

61. Fent K, Weston AA, Caminada D (2006) Ecotoxicology of human pharmaceuticals. Aqua Toxicol 76(2):122-159

62. Nikolaou A, Meric S, Fatta D (2007) Occurrence patterns of pharmaceuticals in water and wastewater environments. Anal Bioanal Chem 387(4):1225-1234

63. Boreen AL, Arnold WA, McNeill K (2003) Photodegradation of pharmaceuticals in the aquatic environment: a review. Aquat Sci 65(4):320-341

64. Packer JL, Werner J Jatch DE et al (2003) Photochemical fate of pharmaceuticals in the environment: naproxen, diclofenac, clofibric acid, and ibuprofen. Aquat Sci 65(4):342-351

65. Huerta-Fontela M, Galceran MT, Ventura F (2011) Occurrence and removal of pharmaceuticals and hormones through drinking water treatment. Water Res 45(3):1432-1442

66. Hirsch R, Ternes T, Haberer K et al (1999) Occurrence of antibiotics in the aquatic environment. Sci Total Environ 225(1-2):109-118 
67. Kümmerer K (2009) Antibiotics in the aquatic environment-a review-part I. Chemosphere 75(4):417-434

68. Osunmakinde CS, Tshabalala OS, Dube S et al (2013) Verification and validation of analytical methods for testing the levels of PPHCPs (pharmaceutical \& personal health care products) in treated drinking water and sewage: report to the Water Research Commission. Water Research Commission Pretoria

69. Kosma Cl, Lambropoulou DA, Albanis TA (2014) Investigation of PPCPs in wastewater treatment plants in Greece: occurrence, removal and environmental risk assessment. Sci Total Environ 466:421-438

70. Camacho-Muñoz D, Martín J, Santos JL et al (2010) Occurrence, temporal evolution and risk assessment of pharmaceutically active compounds in Doñana Park (Spain). J Hazard Mater 183(1-3):602-608

71. Petrović M, Hernando MD, Díaz-Cruz MS et al (2005) Liquid chromatography-tandem mass spectrometry for the analysis of pharmaceutical residues in environmental samples: a review. J Chromatogr A 1067(1-2):1-14

72. Liney KE, Hagger JA, Tyler CR et al (2006) Health effects in fish of longterm exposure to effluents from wastewater treatment works. Environ Health Perspect 114(Suppl 1):81-89

73. Jobling S, Burn RW, Thorpe K et al (2009) Statistical modeling suggests that antiandrogens in effluents from wastewater treatment works contribute to widespread sexual disruption in fish living in English rivers. Environ Health Perspect 117(5):797-802

74. Schriks M, Heringa MB, van der Kooi MM et al (2010) Toxicological relevance of emerging contaminants for drinking water quality. Water Res 44(2):461-476

75. Solé M, Raldua D, Piferrer F et al (2003) Feminization of wild carp, Cyprinus carpio, in a polluted environment: plasma steroid hormones, gonadal morphology and xenobiotic metabolizing system. Comp Biochem Phys C 136(2):145-156

76. Schwaiger J, Ferling H, Mallow U et al (2004) Toxic effects of the nonsteroidal anti-inflammatory drug diclofenac: part I: histopathological alterations and bioaccumulation in rainbow trout. Aquat Toxicol 68(2):141-150

77. Galus M, Jeyaranjaan J, Smith E et al (2013) Chronic effects of exposure to a pharmaceutical mixture and municipal wastewater in zebrafish. Aquat Toxicol 132:212-222

78. Archer E, Petrie B, Kasprzyk-Hordern B et al (2017) The fate of pharmaceuticals and personal care products (PPCPs), endocrine disrupting contaminants (EDCs), metabolites and illicit drugs in a WWTW and environmental waters. Chemosphere 174:437-446

79. Harden CL, Nikolov BG, Kandula P et al (2010) Effect of levetiracetam on testosterone levels in male patients. Epilepsia 51(11):2348-2351

80. Svalheim S, Sveberg L, Mochol M et al (2015) Interactions between antiepileptic drugs and hormones. Seizure 28:12-17

81. Swart N, Pool E (2007) Rapid detection of selected steroid hormones from sewage effluents using an ELISA in the Kuils River water catchment area, South Africa. J Immunoass Immunochem 28(4):395-408

82. Swart JC, Pool EJ, van Wyk JH (2011) The implementation of a battery of in vivo and in vitro bioassays to assess river water for estrogenic endocrine disrupting chemicals. Ecotoxicol Environ Saf 74(1):138-143

83. Baron PA, Love DC, Nachman KE (2014) Pharmaceuticals and personal care products in chicken meat and other food animal products: a market-basket pilot study. Sci Total Environ 490:296-300

84. Done HY, Halden RU (2015) Reconnaissance of 47 antibiotics and associated microbial risks in seafood sold in the United States. J Hazard Mater 282:10-17

85. Pan M, Wong CK, Chu L (2014) Distribution of antibiotics in wastewaterirrigated soils and their accumulation in vegetable crops in the Pearl River Delta, southern China. J Agric Food Chem 62(46):11062-11069

86. Çatalkaya EÇ, Bali U, Şengül F (2003) Photochemical degradation and mineralization of 4-chlorophenol. Environ Sci Pollut Res 10(2):113-120

87. Mirra R, Ribarov C, Valchev D et al (2020) Towards energy efficient onsite wastewater treatment. J Civ Eng Manag 6(7):1218-1226

88. Petrović M, Gonzalez S, Barceló D (2003) Analysis and removal of emerging contaminants in wastewater and drinking water. Trac-Trend Anal Chem 22(10):685-696

89. Ferroudj N, Nzimoto J, Davidson A et al (2013) Maghemite nanoparticles and maghemite/silica nanocomposite microspheres as magnetic
Fenton catalysts for the removal of water pollutants. Appl Catal 136:9-18

90. Halling-Sørensen B, Nielsen SN, Lanzky P et al (1998) Occurrence, fate and effects of pharmaceutical substances in the environment-a review. Chemosphere 36(2):357-393

91. Ibáñez M, Gracia-Lor E, Bijlsma L et al (2013) Removal of emerging contaminants in sewage water subjected to advanced oxidation with ozone. J Hazard Mater 260:389-398

92. Zhang DQ, Gersberg RM, Hua T et al (2013) Fate of pharmaceutical compounds in hydroponic mesocosms planted with Scirpus validus. Environ Pollut 181:98-106

93. Li G, Nie X, Gao Y et al (2016) Can environmental pharmaceuticals be photocatalytically degraded and completely mineralized in water using $\mathrm{g}-\mathrm{C}_{3} \mathrm{~N}_{4} / \mathrm{TiO}_{2}$ under visible light irradiation? - Implications of persistent toxic intermediates. Appl Catal 180:726-732

94. Roberts J, Kumar A, Du J et al (2016) Pharmaceuticals and personal care products (PPCPs) in Australia's largest inland sewage treatment plant, and its contribution to a major Australian river during high and low flow. Sci Total Environ 541:1625-1637

95. Wu H, Fan J, Yang Y et al (2015) Hydrothermal synthesis of graphene$\mathrm{TiO}_{2}$ nanowire with an enhanced photocatalytic activity. Russ J Phys Chem A 89(7):1189-1194

96. Carballa M, Omil F, Lema JM et al (2004) Behavior of pharmaceuticals, cosmetics and hormones in a sewage treatment plant. Water Res 38(12):2918-2926

97. Göbel A, Thomsen A, McArdell CS et al (2005) Occurrence and sorption behavior of sulfonamides, macrolides, and trimethoprim in activated sludge treatment. Environ Sci Technol 39(11):3981-3989

98. Kasprzyk-Hordern B, Dinsdale RM, Guwy AJ (2009) The removal of pharmaceuticals, personal care products, endocrine disruptors and illicit drugs during wastewater treatment and its impact on the quality of receiving waters. Water Res 43(2):363-380

99. Lindqvist N, Tuhkanen T, Kronberg L (2005) Occurrence of acidic pharmaceuticals in raw and treated sewages and in receiving waters. Water Res 39(11):2219-2228

100. Kaur H, Hippargi G, Pophali GR et al (2019) Treatment methods for removal of pharmaceuticals and personal care products from domestic wastewater. In: Pharmaceuticals and personal care products: waste management and treatment technology. Elsevier, Oxford

101. Gomes J, Domingues E, Gmurek M et al (2020) Advanced oxidation processes for recalcitrant compounds removal comparison with biofiltration by Corbicula fluminea. Energy Rep 6:666-671

102. Madikizela LM, Ncube S, Chimuka L (2020) Analysis, occurrence and removal of pharmaceuticals in African water resources: a current status. J Manag 253:109741

103. Berset J-D, Brenneisen R, Mathieu C (2010) Analysis of Ilicit and illicit drugs in waste, surface and lake water samples using large volume direct injection high performance liquid chromatography-electrospray tandem mass spectrometry (HPLC-MS/MS). Chemosphere 81(7):859-866

104. Boleda MR, Galceran MT, Ventura F (2011) Behavior of pharmaceuticals and drugs of abuse in a drinking water treatment plant (DWTP) using combined conventional and ultrafiltration and reverse osmosis (UF/RO) treatments. Environ Pollut 159(6):1584-1591

105. Alvarino T, Suarez S, Lema J et al (2018) Understanding the sorption and biotransformation of organic micropollutants in innovative biological wastewater treatment technologies. Sci Total Environ 615:297-306

106. Anjum M, Miandad R, Waqas M et al (2016) Remediation of wastewater using various nano-materials. Arab J Chem 12(8):4897-4919

107. Lagesson A, Fahlman J, Brodin T et al (2016) Bioaccumulation of five pharmaceuticals at multiple trophic levels in an aquatic food webInsights from a field experiment. Sci Total Environ 568:208-215

108. Mirzaei A, Chen Z, Haghighat F et al (2016) Removal of pharmaceuticals and endocrine disrupting compounds from water by zinc oxide-based photocatalytic degradation: a review. Sustain Cities Soc 27:407-418

109. Zelmanov G, Semiat R (2008) Phenol oxidation kinetics in water solution using iron (3)-oxide-based nano-catalysts. Water Res 42(14):3848-3856

110. Ali ME, El-Aty AMA, Badawy Ml et al (2018) Removal of pharmaceutical pollutants from synthetic wastewater using chemically modified 
biomass of green alga Scenedesmus obliquus. Ecotoxicol Environ Saf 151:144-152

111. LiY, Taggart MA, McKenzie C et al (2019) Utilizing low-cost natural waste for the removal of pharmaceuticals from water: mechanisms, isotherms and kinetics at low concentrations. J Clean Prod 227:88-97

112. Lerman I, Chen Y, Xing B et al (2013) Adsorption of carbamazepine by carbon nanotubes: effects of DOM introduction and competition with phenanthrene and bisphenol A. Environ Pollut 182:169-176

113. Cai N, Larese-Casanova P (2014) Sorption of carbamazepine by commercial graphene oxides: a comparative study with granular activated carbon and multiwalled carbon nanotubes. J Colloid Interface Sci 426:152-161

114. Zhou Y, Apul OG, Karanfil T (2015) Adsorption of halogenated aliphatic contaminants by graphene nanomaterials. Water Res 79:57-67

115. Kasprzyk-Hordern B, Ziółek M, Nawrocki J (2003) Catalytic ozonation and methods of enhancing molecular ozone reactions in water treatment. Appl Catal 46(4):639-669

116. Wang Y, Zhang J, Liu X et al (2012) Synthesis and characterization of activated carbon-coated $\mathrm{SiO}_{2} / \mathrm{TiO}_{2}-\mathrm{xC}$ x nanoporous composites with high adsorption capability and visible light photocatalytic activity. J Mater Chem 135(2-3):579-586

117. Comninellis C, Kapalka A, Malato S et al (2008) Advanced oxidation processes for water treatment: advances and trends for R\&D. J Chem Technol Biotechnol 83(6):769-776

118. Kanakaraju D, Glass BD, Oelgemöller M (2018) Advanced oxidation process-mediated removal of pharmaceuticals from water: a review. $J$ Environ Manag 219:189-207

119. Wang Y, Liu J, Kang D et al (2017) Removal of pharmaceuticals and personal care products from wastewater using algae-based technologies: a review. Rev Environ Sci Bio/Technol 16(4):717-735

120. Gültekin I, Ince NH (2007) Synthetic endocrine disruptors in the environment and water remediation by advanced oxidation processes. J Environ Manag 85(4):816-832

121. Nakata K, Fujishima A (2012) $\mathrm{TiO}_{2}$ photocatalysis: design and applications. J Photochem Photobiol C Photochem Rev 13(3):169-189

122. Byrne C, Subramanian G, Pillai SC (2018) Recent advances in photocatalysis for environmental applications. J Environ Chem Eng 6(3):3531-3555

123. Zhao C, Li W, Liang Y et al (2016) Synthesis of BiOBr/carbon quantum dots microspheres with enhanced photoactivity and photostability under visible light irradiation. Appl Catal A Gen 527:127-136

124. Spasiano D, Marotta R, Malato S et al (2015) Solar photocatalysis: materials, reactors, some commercial, and pre-industrialized applications. A comprehensive approach. Appl Catal 170:90-123

125. Salaeh S, Perisic DJ, Biosic M et al (2016) Diclofenac removal by simulated solar assisted photocatalysis using $\mathrm{TiO}_{2}$-based zeolite catalyst; mechanisms, pathways and environmental aspects. Chem Eng 304:289-302

126. Reina AC, Santos-Juanes L, Sánchez JG et al (2015) Modelling the photo-Fenton oxidation of the pharmaceutical paracetamol in water including the effect of photon absorption (VRPA). Appl Catal 166:295-301

127. de Luna MDG, Briones RM, Su C-C et al (2013) Kinetics of acetaminophen degradation by Fenton oxidation in a fluidized-bed reactor. Chemosphere 90(4):1444-1448

128. Klementova S, Kahoun D, Doubkova L et al (2017) Catalytic photodegradation of pharmaceuticals_-homogeneous and heterogeneous photocatalysis. Photochem Photobiol Sci 16(1):67-71

129. Agustina TE, Ang HM, Vareek VK (2005) A review of synergistic effect of photocatalysis and ozonation on wastewater treatment. J Photochem Photobiol C Photochem Rev 6(4):264-273

130. Xiao J, Xie Y, Cao H (2015) Organic pollutants removal in wastewater by heterogeneous photocatalytic ozonation. Chemosphere 121:1-17

131. Mehrjouei M, Müller S, Möller D (2015) A review on photocatalytic ozonation used for the treatment of water and wastewater. Chem Eng 263:209-219

132. Dobslaw D, Schulz A, Helbich S et al (2017) VOC removal and odor abatement by a low-cost plasma enhanced biotrickling filter process. J Environ Chem Eng 5(6):5501-5511
133. Oller I, Malato S, Sánchez-Pérez J (2011) Combination of advanced oxidation processes and biological treatments for wastewater decontamination - a review. Sci Total Environ 409(20):4141-4166

134. Augugliaro V, Palmisano G, Palmisano L et al (2019) Heterogeneous photocatalysis and catalysis: an overview of their distinctive features. In: Heterogeneous photocatalysis. Elsevier, Amsterdam, pp 1-24

135. Ortiz I, Rivero MJ, Margallo M (2019) Advanced oxidative and catalytic processes. In: Sustainable water and wastewater processing. Elsevier, Amsterdam, pp 161-201

136. Eskandarian MR, Choi H, Fazli M et al (2016) Effect of UV-LED wavelengths on direct photolytic and $\mathrm{TiO}_{2}$ photocatalytic degradation of emerging contaminants in water. Chem Eng 300:414-422

137. Akhavan $\mathrm{O}$ (2009) Lasting antibacterial activities of $\mathrm{Ag}-\mathrm{TiO}_{2} / \mathrm{Ag} / \mathrm{a}-\mathrm{TiO} \mathrm{O}_{2}$ nanocomposite thin film photocatalysts under solar light irradiation. J Colloid Interface Sci 336(1):117-124

138. Lin S-T, Thirumavalavan M, Jiang T-Y et al (2014) Synthesis of ZnO/Zn nano photocatalyst using modified polysaccharides for photodegradation of dyes. Carbohydr Polym 105:1-9

139. Theingi M, Tun KT, Aung NN (2019) Preparation, characterization and optical property of $\mathrm{LaFeO}_{3}$ nanoparticles via sol-gel combustion method. SciMed J 1(3):151-157

140. Rehman GU, Tahir M, Goh P et al (2019) Facile synthesis of GO and $\mathrm{g}-\mathrm{C}_{3} \mathrm{~N}_{4}$ nanosheets encapsulated magnetite ternary nanocomposite for superior photocatalytic degradation of phenol. Environ Pollut 253:1066-1078

141. Asadzadeh-Khaneghah S, Habibi-Yangjeh A, Yubuta K (2019) Novel $\mathrm{g}-\mathrm{C}_{3} \mathrm{~N}_{4}$ nanosheets/CDs/BiOCl photocatalysts with exceptional activity under visible light. J Am Ceram Soc 102(3):1435-1453

142. Bahnemann D (2004) Photocatalytic water treatment: solar energy applications. J Sol Energy 77(5):445-459

143. Qiu LF, Zhou ZW, Qiu XB et al (2018) Synthesis and photocatalytic degradation performance of g- $\mathrm{C}_{3} \mathrm{~N}_{4} / \mathrm{CQDs} / \mathrm{SAPO}-5$ ternary composite. In: Key engineering materials. Trans Tech Publ, Pfaffikon

144. Cheng Y, Lin Y, Xu J et al (2016) Surface plasmon resonance enhanced visible-light-driven photocatalytic activity in Cu nanoparticles covered $\mathrm{Cu}_{2} \mathrm{O}$ microspheres for degrading organic pollutants. Appl Surf Sci 366:120-128

145. Li C, Yu S, Che H et al (2018) Fabrication of Z-scheme heterojunction by anchoring mesoporous $\gamma-\mathrm{Fe}_{2} \mathrm{O}_{3}$ nanospheres on $\mathrm{g}-\mathrm{C}_{3} \mathrm{~N}_{4}$ for degrading tetracycline hydrochloride in water. ACS Sustain Chem Eng 6(12):16437-16447

146. Saleh R, Djaja NF (2014) UV light photocatalytic degradation of organic dyes with Fe-doped $\mathrm{ZnO}$ nanoparticles. Superlattice Microstruct 74:217-233

147. Ismail AA (2012) Facile synthesis of mesoporous Ag-loaded $\mathrm{TiO}_{2}$ thin film and its photocatalytic properties. Microporous Mesoporous Mater 149(1):69-75

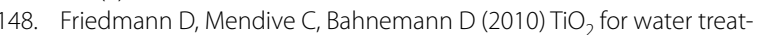
ment: parameters affecting the kinetics and mechanisms of photocatalysis. Appl Catal 99(3-4):398-406

149. Zhang J, Zhou P, Liu J et al (2014) New understanding of the difference of photocatalytic activity among anatase, rutile and brookite $\mathrm{TiO}_{2}$. Phys Chem Chem Phys 16(38):20382-20386

150. Awfa D, Ateia M, Fujii M et al (2019) Novel magnetic carbon nanotube$\mathrm{TiO}_{2}$ composites for solar light photocatalytic degradation of pharmaceuticals in the presence of natural organic matter. J Water Process Eng 31:100836

151. Rimoldi L, Meroni D, Falletta E et al (2017) Emerging pollutant mixture mineralization by $\mathrm{TiO}_{2}$ photocatalysts. The role of the water medium. Photochem Photobiol Sci 16(1):60-66

152. He Y, Sutton NB, Rijnaarts HH et al (2016) Degradation of pharmaceuticals in wastewater using immobilized $\mathrm{TiO}_{2}$ photocatalysis under simulated solar irradiation. Appl Catal 182:132-141

153. Hapeshi E, Achilleos A, Vasquez MI et al (2010) Drugs degrading photocatalytically: kinetics and mechanisms of ofloxacin and atenolol removal on titania suspensions. Water Res 44(6):1737-1746

154. Thevenet F, Guaitella O, Herrmann J et al (2005) Photocatalytic degradation of acetylene over various titanium dioxide-based photocatalysts. Appl Catal 61(1-2):58-68 
155. Noorimotlagh Z, Kazeminezhad I, Jaafarzadeh N et al (2018) WITHDRAWN: nonylphenol degradation using immobilized carbon-doped $\mathrm{TiO}_{2}$ (Rutile/Anatase) under visible illumination: effect of operational parameters and degradation pathway. Chem Eng J. https://doi. org/10.1016/j.cej.2018.02.077

156. Dzinun $H$, Othman MHD, Ismail AF et al (2015) Photocatalytic degradation of nonylphenol by immobilized $\mathrm{TiO}_{2}$ in dual layer hollow fibre membranes. Chem Eng 269:255-261

157. Wang X, Hu Z, Chen Y et al (2009) A novel approach towards highperformance composite photocatalyst of $\mathrm{TiO}_{2}$ deposited on activated carbon. Appl Surf Sci 255(7):3953-3958

158. Długosz M, Kwiecień A, Żmudzki P et al (2015) A hybrid adsorbent/visible light photocatalyst for the abatement of microcystin-LR in water. ChemComm 51(36):7649-7652

159. Janotti A, Van de Walle CG (2009) Fundamentals of zinc oxide as a semiconductor. Rep Prog Phys 72(12):126501

160. Di Mauro A, Fragala ME, Privitera V et al (2017) ZnO for application in photocatalysis: from thin films to nanostructures. Mater Sci Semicond Process 69:44-51

161. Teixeira S, Gurke R, Eckert $\mathrm{H}$ et al (2016) Photocatalytic degradation of pharmaceuticals present in conventional treated wastewater by nanoparticle suspensions. J Environ Chem Eng 4(1):287-292

162. Ismael M (2020) The photocatalytic performance of the $\mathrm{ZnO} / \mathrm{g}-\mathrm{C}_{3} \mathrm{~N}_{4}$ composite photocatalyst toward degradation of organic pollutants and its inactivity toward hydrogen evolution: the influence of light irradiation and charge transfer. Chem Phys Lett 739:136992

163. Dirany N, Arab M, Madigou V et al (2016) A facile one step route to synthesize $\mathrm{WO}_{3}$ nanoplatelets for $\mathrm{CO}$ oxidation and photodegradation of RhB: microstructural, optical and electrical studies. RSC Adv 6(73):69615-69626

164. Chen G, Bian S, Guo C-Y et al (2019) Insight into the Z-scheme heterostructure $\mathrm{WO}_{3} / \mathrm{g}-\mathrm{C}_{3} \mathrm{~N}_{4}$ for enhanced photocatalytic degradation of methyl orange. Mater Lett 236:596-599

165. Wang H, Yang X, Zi J et al (2016) High photocatalytic degradation of tetracycline under visible light with $\mathrm{Ag} / \mathrm{AgCl} /$ activated carbon composite plasmonic photocatalyst. J Ind Eng Chem 35:83-92

166. Santhosh C, Velmurugan V, Jacob G et al (2016) Role of nanomaterials in water treatment applications: a review. Chem Eng 306:1116-1137

167. Leary R, Westwood A (2011) Carbonaceous nanomaterials for the enhancement of $\mathrm{TiO}_{2}$ photocatalysis. Carbon 49(3):741-772

168. Puma GL, Bono A, Krishnaiah D et al (2008) Preparation of titanium dioxide photocatalyst loaded onto activated carbon support using chemical vapor deposition: a review paper. J Hazard Mater 157(2-3):209-219

169. Jamil TS, Ghaly MY, Fathy NA et al (2012) Enhancement of $\mathrm{TiO}_{2}$ behavior on photocatalytic oxidation of $\mathrm{MO}$ dye using $\mathrm{TiO}_{2} / \mathrm{AC}$ under visible irradiation and sunlight radiation. Sep Purif Technol 98:270-279

170. Bhatnagar A, Hogland W, Marques M et al (2013) An overview of the modification methods of activated carbon for its water treatment applications. Chem Eng 219:499-511

171. Ateia M, Apul OG, Shimizu Y et al (2017) Elucidating adsorptive fractions of natural organic matter on carbon nanotubes. Environ Sci Technol 51(12):7101-7110

172. Woan K, Pyrgiotakis G, Sigmund W (2009) Photocatalytic carbon-nanotube- $\mathrm{TiO}_{2}$ composites. J Adv Mater 21(21):2233-2239

173. Alalm MG, Tawfik A, Ookawara S (2015) Combined solar advanced oxidation and PAC adsorption for removal of pesticides from industrial wastewater. J Mater Environ Sci 6(3):800-809

174. Salih HH, Sorial GA, Patterson CL et al (2012) Removal of trichloroethylene by activated carbon in the presence and absence of $\mathrm{TiO}_{2}$ nanoparticles. Water Air Soil Pollut 223(5):2837-2847

175. Anis SF, Khalil A, Singaravel G et al (2016) A review on the fabrication of zeolite and mesoporous inorganic nanofibers formation for catalytic applications. Microporous Mesoporous Mater 236:176-192

176. Takeuchi M, Kimura T, Hidaka M et al (2007) Photocatalytic oxidation of acetaldehyde with oxygen on $\mathrm{TiO}_{2} / \mathrm{ZSM}-5$ photocatalysts: effect of hydrophobicity of zeolites. J Catal 246(2):235-240

177. Takeuchi M, Hidaka M, Anpo M (2012) Efficient removal of toluene and benzene in gas phase by the $\mathrm{TiO}_{2} / \mathrm{Y}$-zeolite hybrid photocatalyst. J Hazard Mater 237:133-139
178. Khraisheh M, Kim J, Campos L et al (2013) Removal of carbamazepine from water by a novel $\mathrm{TiO}_{2}$-coconut shell powder/UV process: composite preparation and photocatalytic activity. Environ Eng Sci 30(9):515-526

179. Shaibu SE, Adekola FA, Adegoke HI et al (2014) A comparative study of the adsorption of methylene blue onto synthesized nanoscale zerovalent iron-bamboo and manganese-bamboo composites. J Mater Sci 7(6):4493-4507

180. Fagbayigbo BO, Opeolu BO, Fatoki OS et al (2017) Removal of PFOA and PFOS from aqueous solutions using activated carbon produced from Vitis vinifera leaf litter. Environ Sci Pollut Res 24(14):13107-13120

181. Omo-Okoro PN, Daso AP, Okonkwo JO (2018) A review of the application of agricultural wastes as precursor materials for the adsorption of per-and polyfluoroalkyl substances: a focus on current approaches and methodologies. Environ Technol Innov 9:100-114

182. Arana J, Dona-Rodrıguez J, Rendón ET et al (2003) TiO2 activation by using activated carbon as a support: Part I. Surface characterisation and decantability study. Appl Catal 44(2):161-172

183. Gopiraman M, Kim IS (2018) Carbon nanocomposites: preparation and its application in catalytic organic transformations. In: Nanocompositesrecent evolutions. IntechOpen, London

184. Orha C, Pode R, Manea F et al (2017) Titanium dioxide-modified activated carbon for advanced drinking water treatment. Process Saf Environ 108:26-33

185. Tan Q, Xu Y, Yang J et al (2013) Preparation and electrochemical properties of the ternary nanocomposite of polyaniline/activated carbon/ $/ \mathrm{iO}_{2}$ nanowires for supercapacitors. Electrochim Acta 88:526-529

186. Vinayagam M, Ramachandran S, Ramya V et al (2018) Photocatalytic degradation of orange $\mathrm{G}$ dye using $\mathrm{ZnO} /$ biomass activated carbon nanocomposite. J Environ Chem Eng 6(3):3726-3734

187. lijima S (1991) Helical microtubules of graphitic carbon. Nature 354(6348):56-58

188. Wei H, Deng S, Huang Q et al (2013) Regenerable granular carbon nanotubes/alumina hybrid adsorbents for diclofenac sodium and carbamazepine removal from aqueous solution. Water Res 47(12):4139-4147

189. Agnihotri S, Mota JP, Rostam-Abadi M et al (2006) Adsorption site analysis of impurity embedded single-walled carbon nanotube bundles. Carbon 44(12):2376-2383

190. Ye S, Zhou X, Xu Y et al (2019) Photocatalytic performance of multiwalled carbon nanotube/BiVO ${ }_{4}$ synthesized by electro-spinning process and its degradation mechanisms on oxytetracycline. Chem Eng 373:880-890

191. Marques RR, Sampaio MJ, Carrapiço PM et al (2013) Photocatalytic degradation of caffeine: developing solutions for emerging pollutants. Catal Today 209:108-115

192. Samsudin MFR, Bacho N, Sufian S et al (2019) Photocatalytic degradation of phenol wastewater over Z-scheme g- $\mathrm{C}_{3} \mathrm{~N}_{4} / \mathrm{CNT} / \mathrm{BiVO}_{4}$ heterostructure photocatalyst under solar light irradiation. J Mol Liq 277:977-988

193. Samsudin MFR, Mahmood A, Sufian S (2018) Enhanced photocatalytic degradation of wastewater over $\mathrm{RGO}-\mathrm{TiO}_{2} / \mathrm{BiVO}_{4}$ photocatalyst under solar light irradiation. J Mol Liq 268:26-36

194. An G, Ma W, Sun Z et al (2007) Preparation of titania/carbon nanotube composites using supercritical ethanol and their photocatalytic activity for phenol degradation under visible light irradiation. Carbon 45(9):1795-1801

195. Hu C, Lu T, Chen F et al (2013) A brief review of graphene-metal oxide composites synthesis and applications in photocatalysis. J Chin Adv Mater Soc 1(1):21-39

196. Ersan G, Apul OG, Perreault F et al (2017) Adsorption of organic contaminants by graphene nanosheets: a review. Water Res 126:385-398

197. Wang Q, Arash B (2014) A review on applications of carbon nanotubes and graphenes as nano-resonator sensors. Comput Mater Sci 82:350-360

198. Bonaccorso F, Colombo L, Yu G et al (2015) Graphene, related twodimensional crystals, and hybrid systems for energy conversion and storage. J Sci 347(6217):1246501

199. Mittal G, Dhand V, Rhee KY et al (2015) A review on carbon nanotubes and graphene as fillers in reinforced polymer nanocomposites. J Ind Eng Chem 21:11-25 
200. Suárez-lglesias O, Collado S, Oulego P et al (2017) Graphene-family nanomaterials in wastewater treatment plants. Chem Eng 313:121-135

201. Fei P, Wang Q, Zhong M et al (2016) Preparation and adsorption properties of enhanced magnetic zinc ferrite-reduced graphene oxide nanocomposites via a facile one-pot solvothermal method. J Alloys Compd 685:411-417

202. Shen J, Ma G, Zhang J et al (2015) Facile fabrication of magnetic reduced graphene oxide- $\mathrm{ZnFe}_{2} \mathrm{O}_{4}$ composites with enhanced adsorption and photocatalytic activity. Appl Surf Sci 359:455-468

203. Brodie BC (1859) XIII. On the atomic weight of graphite. Philos Trans R Soc B 149:249-259

204. Poh HL, Šaněk F, Ambrosi A et al (2012) Graphenes prepared by Staudenmaier, Hofmann and Hummers methods with consequent thermal exfoliation exhibit very different electrochemical properties. Nanoscale 4(11):3515-3522

205. Stankovich S, Dikin DA, Piner RD et al (2007) Synthesis of graphenebased nanosheets via chemical reduction of exfoliated graphite oxide. Carbon 45(7):1558-1565

206. Ma L, Chen A, Zhang Z et al (2012) In-situ fabrication of CNT/TiO interpenetrating network film on nickel substrate by chemical vapour deposition and application in photoassisted water electrolysis. Catal Commun 21:27-31

207. Lin Z, Yao Y, Li Z et al (2010) Solvent-assisted thermal reduction of graphite oxide. J Phys Chem 114(35):14819-14825

208. Shao Y, Wang J, Engelhard M et al (2010) Facile and controllable electrochemical reduction of graphene oxide and its applications. J Mater Chem 20(4):743-748

209. Morales-Torres S, Pastrana-Martínez LM, Figueiredo JL et al (2013) Graphene oxide-P25 photocatalysts for degradation of diphenhydramine pharmaceutical and methyl orange dye. Appl Surf Sci 275:361-368

210. Gu Y, Yu Y, Zou J et al (2018) The ultra-rapid synthesis of $\mathrm{rGO} / \mathrm{g}-\mathrm{C}_{3} \mathrm{~N}_{4}$ composite via microwave heating with enhanced photocatalytic performance. Mater Lett 232:107-109

211. Kim IY, Lee JM, Kim TW et al (2012) A strong electronic coupling between graphene nanosheets and layered titanate nanoplates: a soft-chemical route to highly porous nanocomposites with improved photocatalytic activity. Small Methods 8(7):1038-1048

212. Sun J, Zhang H, Guo L-H et al (2013) Two-dimensional interface engineering of a titania-graphene nanosheet composite for improved photocatalytic activity. ACS Appl Mater Inter 5(24):13035-13041

213. Shanavas S, Roopan SM, Priyadharsan A et al (2019) Computationally guided synthesis of (2D/3D/2D) $\mathrm{rGO} / \mathrm{Fe}_{2} \mathrm{O}_{3} / \mathrm{g}-\mathrm{C}_{3} \mathrm{~N}_{4}$ nanostructure with improved charge separation and transportation efficiency for degradation of pharmaceutical molecules. Appl Catal 255:117758

214. Nawaz M, Miran W, Jang J et al (2017) One-step hydrothermal synthesis of porous $3 \mathrm{D}$ reduced graphene oxide/ $/ \mathrm{Ti}_{2}$ aerogel for carbamazepine photodegradation in aqueous solution. Appl Catal 203:85-95

215. Lin T, Yu S, Chen W (2016) Occurrence, removal and risk assessment of pharmaceutical and personal care products (PPCPs) in an advanced drinking water treatment plant (ADWTP) around Taihu Lake in China. Chemosphere 152:1-9

216. Mori M, Sammes NM, Tompsett GA (2000) Fabrication processing condition for dense sintered $\mathrm{La} 0.6 \mathrm{AE} 0.4 \mathrm{MnO}_{3}$ perovskites synthesized by the coprecipitation method ( $\mathrm{AE}=\mathrm{Ca}$ and $\mathrm{Sr}$ ). J Power Sources 86(1-2):395-400

217. Huang G, Lu C-H, Yang H-H (2019) Magnetic nanomaterials for magnetic bioanalysis. In: Novel nanomaterials for biomedical, environmental and energy applications. Elsevier, Amsterdam, pp 89-109

218. Feng S-H, Li G-H (2017) Hydrothermal and solvothermal syntheses. In: Modern inorganic synthetic chemistry. Elsevier, Amsterdam, pp 73-104

219. Salavati-Niasari M, Davar F, Mazaheri M (2008) Synthesis of $\mathrm{Mn}_{3} \mathrm{O}_{4}$ nanoparticles by thermal decomposition of a [bis (salicylidiminato) manganese (II)] complex. Polyhedron 27(17):3467-3471

220. Soni H, Kumar N, Patel K et al (2016) Photo catalytic efficiency and kinetic studies of $\mathrm{ZnO}$ nanoparticles for the removal of basic dye Rhodamine B. Desalin Water Treat 57(42):19857-19864

221. Zhang H, Fu X, Niu S et al (2008) Synthesis and photoluminescence properties of $\mathrm{Eu}^{3+}$-doped $\mathrm{AZrO}_{3}(\mathrm{~A}=\mathrm{Ca}$, $\mathrm{Sr}, \mathrm{Ba})$ perovskite. J Alloy Compd 459(1-2):103-106
222. Wang B-LL-L, Hu (2005) Effect of water content in sol on optical properties of hybrid sol-gel derived $\mathrm{TiO}_{2} / \mathrm{SiO}_{2} /$ ormosil film. Mater Chem Phys 89(2-3):417-422

223. Marugán J, Christensen P, Egerton T et al (2009) Synthesis, characterization and activity of photocatalytic sol-gel $\mathrm{TiO}_{2}$ powders and electrodes. Appl Catal 89(1-2):273-283

224. Lin X, Liu C, Wang J et al (2019) Graphitic carbon nitride quantum dots and nitrogen-doped carbon quantum dots co-decorated with $\mathrm{BiVO}_{4}$ microspheres: a ternary heterostructure photocatalyst for water purifcation. Sep Purif Technol 226:117-127

225. Wang X, Maeda K, Thomas A et al (2009) A metal-free polymeric photocatalyst for hydrogen production from water under visible light. Nat Mater 8(1):76-80

226. Ong W-J, Tan L-L, Ng YH et al (2016) Graphitic carbon nitride ( $\left(-\mathrm{C}_{3} \mathrm{~N}_{4}\right)$ based photocatalysts for artificial photosynthesis and environmental remediation: are we a step closer to achieving sustainability? Chem Rev 116(12):7159-7329

227. Rono N, Kibet JK, Martincigh BS et al (2020) A review of the current status of graphitic carbon nitride. Crit Rev Solid State Mater Sci. https:// doi.org/10.1080/10408436.2019.1709414

228. Liu J, Wang H, Chen ZP et al (2015) Microcontact-printing-assisted access of graphitic carbon nitride films with favorable textures toward photoelectrochemical application. J Adv Mater 27(4):712-718

229. Yang P, Wang J, Yue G et al (2020) Constructing mesoporous $g-C_{3} N_{4} /$ $\mathrm{ZnO}$ nanosheets catalyst for enhanced visible-light driven photocataIytic activity. J Photochem Photobiol A Chem 388:112169

230. Maeda K, Wang X, Nishihara Y et al (2009) Photocatalytic activities of graphitic carbon nitride powder for water reduction and oxidation under visible light. J Phys Chem 113(12):4940-4947

231. Kang S, Zhang L, He M et al (2018) "Alternated cooling and heating" strategy enables rapid fabrication of highly-crystalline $\mathrm{g}-\mathrm{C}_{3} \mathrm{~N}_{4}$ nanosheets for efficient photocatalytic water purification under visible light irradiation. Carbon 137:19-30

232. Zhong $\mathrm{Q}$, Lan $\mathrm{H}$, Zhang $\mathrm{M}$ et al (2020) Preparation of heterostructure $\mathrm{g}-\mathrm{C}_{3} \mathrm{~N}_{4} / \mathrm{ZnO}$ nanorods for high photocatalytic activity on different pollutants (MB, RhB, Cr (VI) and eosin). Ceram Int. https://doi.org/10.1016/j. ceramint.2020.01.265

233. Liang S, Zhang D, Pu X et al (2019) A novel $A g_{2} \mathrm{O} / \mathrm{g}-\mathrm{C}_{3} \mathrm{~N}_{4}$ pn heterojunction photocatalysts with enhanced visible and near-infrared light activity. Sep Purif Technol 210:786-797

234. He Y, Ma Z, Junior LB (2020) Distinctive binary g- $\mathrm{C}_{3} \mathrm{~N}_{4} / \mathrm{MoS}_{2}$ heterojunctions with highly efficient ultrasonic catalytic degradation for levofloxacin and methylene blue. Ceram Int. https://doi.org/10.1016/j. ceramint.2020.01.287

235. Liu G, Liao M, Zhang Z et al (2020) Enhanced photodegradation performance of Rhodamine $B$ with $g-C_{3} N_{4}$ modified by carbon nanotubes. Sep Purif Technol 244:116618

236. Zhang S, Hu C, Ji H et al (2019) Facile synthesis of nitrogen-deficient mesoporous graphitic carbon nitride for highly efficient photocatalytic performance. Appl Surf Sci 478:304-312

237. Li J, Liu E, Ma Y et al (2016) Synthesis of $\mathrm{MoS}_{2} / \mathrm{g}-\mathrm{C}_{3} \mathrm{~N}_{4}$ nanosheets as $2 \mathrm{D}$ heterojunction photocatalysts with enhanced visible light activity. Appl Surf Sci 364:694-702

238. Xue W, Hu X, Liu E et al (2018) Novel reduced graphene oxide-supported Cd0. $5 \mathrm{Zn0} 0.5 \mathrm{~S} / \mathrm{g}-\mathrm{C}_{3} \mathrm{~N}_{4}$ Z-scheme heterojunction photocatalyst for enhanced hydrogen evolution. Appl Surf Sci 447:783-794

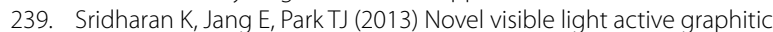
$\mathrm{C}_{3} \mathrm{~N}_{4}-\mathrm{TiO}_{2}$ composite photocatalyst: synergistic synthesis, growth and photocatalytic treatment of hazardous pollutants. Appl Catal 142:718-728

240. Singh J, Arora A, Basu S (2019) Synthesis of coral like $W_{3} / g-C_{3} N_{4}$ nanocomposites for the removal of hazardous dyes under visible light. J Alloy Compd 808:151734

241. Nekouei F, Nekouei S, Pouzesh M et al (2020) Porous-CdS/Cu $\mathrm{O} /$ graphitic- $\mathrm{C}_{3} \mathrm{~N}_{4}$ dual pn junctions as highly efficient photo/catalysts for degrading ciprofloxacin and generating hydrogen using solar energy. Chem Eng 385:123710

242. Chen W, Hua Y-X, Wang Y et al (2017) Two-dimensional mesoporous $\mathrm{g}-\mathrm{C}_{3} \mathrm{~N}_{4}$ nanosheet-supported $\mathrm{Mgln}_{2} \mathrm{~S}_{4}$ nanoplates as visible-light-active heterostructures for enhanced photocatalytic activity. J Catal 349:8-18 
243. Li G, Wang B, Zhang J et al (2019) Rational construction of a direct Z-scheme $\mathrm{g}-\mathrm{C}_{3} \mathrm{~N}_{4} / \mathrm{CdS}$ photocatalyst with enhanced visible light photocatalytic activity and degradation of erythromycin and tetracycline. Appl Surf Sci 478:1056-1064

244. Hernández-Uresti D, Vázquez A, Sanchez-Martinez D, Obregón S (2016) Performance of the polymeric $g-C_{3} N_{4}$ photocatalyst through the degradation of pharmaceutical pollutants under UV-vis irradiation. J Photochem Photobiol A Chem 324:47-52

245. Kurniawan $T A$, Yanyan $\mathrm{L}$, Ouyang $\mathrm{T}$ et al (2018) $\mathrm{BaTiO}_{3} / \mathrm{TiO}_{2}$ compositeassisted photocatalytic degradation for removal of acetaminophen from synthetic wastewater under UV-vis irradiation. Mater Sci Semicond Process 73:42-50

246. Jingyu H, Ran Y, Zhaohui L et al (2019) In-situ growth of ZnO globular on $\mathrm{g}-\mathrm{C}_{3} \mathrm{~N}_{4}$ to fabrication binary heterojunctions and their photocataIytic degradation activity on tetracyclines. Solid State Sci 92:60-67

247. Song Y, Qi J, Tian J et al (2018) Construction of $\mathrm{Ag} / \mathrm{g}-\mathrm{C}_{3} \mathrm{~N}_{4}$ photocatalysts with visible-light photocatalytic activity for sulfamethoxazole degradation. Chem Eng J 341:547-555

248. Kumar A, Khan M, Zeng X, Lo IM (2018) Development of g- $\mathrm{C}_{3} \mathrm{~N}_{4} / \mathrm{TiO}_{2} /$ $\mathrm{Fe}_{3} \mathrm{O}_{4} @ \mathrm{SiO}_{2}$ heterojunction via sol-gel route: a magnetically recyclable direct contact Z-scheme nanophotocatalyst for enhanced photocatalytic removal of ibuprofen from real sewage effluent under visible light. Chem Eng J 353:645-656

249. Yan J, Song Z, Wang $X$ et al (2019) Enhanced photocatalytic activity of ternary $\mathrm{Ag}_{3} \mathrm{PO}_{4} / \mathrm{GO} / \mathrm{g}-\mathrm{C}_{3} \mathrm{~N}_{4}$ photocatalysts for Rhodamine B degradation under visible light radiation. Appl Surf Sci 466:70-77

250. Wang W, Han Q, Zhu Z et al (2019) Enhanced photocatalytic degradation performance of organic contaminants by heterojunction photocatalyst $\mathrm{BiVO}_{4} / \mathrm{TiO}_{2} / \mathrm{RGO}$ and its compatibility on four different tetracycline antibiotics. Adv Powder Technol 30:1882-1896

251. Wen X-J, Niu C-G, Zhang L et al (2018) A novel $\mathrm{Ag}_{2} \mathrm{O} / \mathrm{CeO}_{2}$ heterojunction photocatalysts for photocatalytic degradation of enrofloxacin: possible degradation pathways, mineralization activity and an in depth mechanism insight. Appl Catal 221:701-714

252. Zhou Y, Li J, Liu C et al (2018) Construction of 3D porous $\mathrm{g}-\mathrm{C}_{3} \mathrm{~N}_{4} / \mathrm{AgBr} /$ rGO composite for excellent visible light photocatalytic activity. Appl Surf Sci 458:586-596

253. YuChen WXA, Mei W et al (2017) Photocatalytic and electrochemical performance of three-dimensional reduced graphene oxide $/ \mathrm{WS}_{2} / \mathrm{Mg}$ doped ZnO composites. Appl Surf Sci 400:129-138

254. Cui C, Xie J, Lin D et al (2019) Recent progress in carbon-based materials as catalysts for electrochemical and photocatalytic water splitting. In: Carbon based nanomaterials for advanced thermal and electrochemical energy storage and conversion. Elsevier, Amsterdam, pp 173-200

255. Samsudin MFR, Bacho N, Sufian S (2018) Recent development of graphitic carbon nitride-based photocatalyst for environmental pollution remediation. In: Nanocatalysts. IntechOpen, London

256. Ikram S (2016) Role of nanomaterials and their applications as photocatalyst and senors: a review. Nano Res 2:10

\section{Publisher's Note}

Springer Nature remains neutral with regard to jurisdictional claims in published maps and institutional affiliations.
Ready to submit your research? Choose BMC and benefit from:

- fast, convenient online submission

- thorough peer review by experienced researchers in your field

- rapid publication on acceptance

- support for research data, including large and complex data types

- gold Open Access which fosters wider collaboration and increased citations

- maximum visibility for your research: over $100 \mathrm{M}$ website views per year

At BMC, research is always in progress.

Learn more biomedcentral.com/submissions 